\title{
Long-Term Operation of VVER Power Plants
}

\author{
Tamás János Katona \\ Nuclear Power Plant Paks Ltd. \\ Hungary
}

\section{Introduction}

The VVER reactors are light-water-moderated and water-cooled i.e. pressurized water reactors (PWRs). The name comes from Russian "водо-водяной энергетический реактор" which transliterates as Vodo-Vodyanoi Energetichesky Reaktor (Water-Water Energetic Reactor WWER but the Russian type acronym VVER is more often used). The VVERs were developed in the 1960s. There are 52 Russian designed VVER-type pressurized water nuclear power plants operating in the world today under of 437 nuclear power plants (for the latest operational statistics VVER plants see IAEA PRIS database www.iaea.org). The cumulative time of safe operation of VVER reactors currently exceeds 1200 reactoryears. The first three VVERs were built in Russia and in Eastern-Germany in 1964-1970 and they were operated up to 1990. The first standard series of VVER have a nominal electrical capacity of $440 \mathrm{MW}$ and the second standard series have the capacity of $1000 \mathrm{MW}$. There are two basic types of VVER-440 reactors, which are based on different safety philosophies. The VVER-440/230 type is a Generation I design while the VVER-440/213 is representing already the Generation II reactor design with reduced pressure containment. Outside Russia all VVER-440/230 type plants of the standard design are already shut down. There are two specific VVER-440 designs in operation the Loviisa NPP with reduced pressure western type containment and the Armenian Medzamor NPP. In the VVER 1000 MW series, there is a gradual design development through the five oldest plants (small series) while the rest of the operating plants represent the standardised VVER-1000/320 model. The VVER-1000 units commissioned recently and those currently being under construction are improved versions of the VVER-1000/320; for example the Tianwan (China) plant with AES-91 type units and the Kudankulam (India) plant with AES-92 type units. New VVER models e.g. the AES-2006 design is being considered for future bids. The older types of VVER-1000 are of Generation II while the new evolutionary models of large VVER already exhibit Generation III features.

The design operational lifetime of the VVER plants is generally 30 years. Exceptions are only the newly designed and operating VVER-1000 units with 50 or 60 years of designed operational lifetime. A great majority of VVER plants are aged nearing the end of the design-lifetime. Except Russia the VVER operating countries are dependent on nuclear power production for example the Nuclear Power Plant Paks in Hungary provided $40 \%$ of domestic production in 2010. The nuclear power capacities in these countries ensure the necessary diversity of power generation and contribute to the security of supply. Therefore, the VVER owners in Central and Eastern Europe intend to keep their plants in operation via implementing plant lifetime management (PLiM) programmes with the intention of 
ensuring safe and financially viable operation in the long term. The PLiM activity and strategy of VVER operators is presented in (Katona, 2010).

The possibility of extension of operational lifetime of VVER-440/213 plants was recognised already in 1992 based on assessment of robustness of the design good technical condition of the plants and synergy between safety upgrading measures and overall condition of the plants (Katona\&Bajsz, 1992).

In all VVER operating countries, the lifetime management had the explicit goal of ensuring prolongation of operational lifetime see e.g. (Roesenergoatom, 2003).

The operational license of the four VVER-440/213 units at Paks NPP Hungary is nominally limited to the design lifetime of 30 years. Prolongation by additional 20 years of the operational lifetime is however feasible. The first formal step of licence renewal of Paks NPP has been made in 2008 and the relicensing process is going on.

In Ukraine, the nuclear shear in the domestic production of electricity is approximately $48 \%$ while the nuclear power plant comprises $26.6 \%$ of total installed capacity. There is a strong interest to extend the operational lifetime of all Ukrainian NPPs. The operational license of the VVER-440/213 type Units 1 and 2 at Rivne NPP Ukraine has been renewed by additional 20 years under condition of performing safety assessment after ten years of prolonged operation. The extension of operational lifetime is a generic strategy of operators of VVER-440/213 plants in Czech Republic and Slovakia.

The Loviisa NPP in Finland (a non standard VVER-440 design) prolonged the operation up to the next Periodic Safety Review (10 years).

The operational lifetime of the VVER plants in Russia will be extended by 15 to 25 years; the four oldest VVER-440/230 units (Novovoronesh NPP Unit 34 Kola NPP Unit 1 and 2) have already received a 15 licence for extended operation. The VVER-440/213 type units (Kola NPP Unit 3 and 4) also prepared to 15 years prolongation of operational licence. Among VVER-1000 plants, the Novovoronesh Unit 5 is prepared to 25 years prolongation of operation after an excessive safety upgrading and modernisation programme.

Increasing the competitiveness by power up-rate is also a general element of industry strategies in all VVER-operating countries. The VVER-440 type units at Loviisa NPP are operated at $\sim 510$ MWe power level. At Paks NPP enhancement of the reactor thermal power by $8 \%$ increased the power output up-to $500 \mathrm{MW}$ and the commercial competitiveness of the plant. Slovenské Elektrárne also implemented a programme of progressive power up-rate of Bochunice V2 NPP and the net capacity of $472 \mathrm{MW}$ is already achieved. Similar projects are

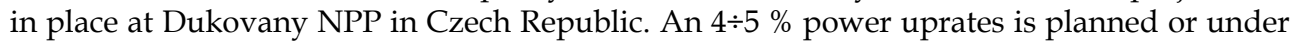
implementation practically at all VVER plants in Russia except the oldest plants which provide approximately 300 MWe extra generating capacity.

VVER operators implemented extensive safety upgrading and modernisation programmes during last decades and achieved an internationally accepted level of safety. Generally, safety deficiencies do not inhibit the long-term operation of the VVER plants.

Considerable progress has been achieved at VVER plants with respect to the improvement of the performance and plant reliability too. The load factor of majority of VVER plants is over $80 \%$ at some plants e.g. at Paks and Dukovany NPP it is around $90 \%$.

In this chapter - after an overview of basic technical features of VVER plants - the development and implementation of PLiM programmes for VVER plants will be presented. The methods for ensuring long-term operation are focused on the type and lifetime limiting ageing/degradation mechanisms of the most important systems structures and components. The integration of the plant activities/programmes into coherent PLiM programme will be 
demonstrated taking into account the frame of regulatory requirements regarding long-term operation. The role of the international research and co-operation environment affecting the lifetime management of VVER plants will also be presented. The presentation of the PLiM and long-term operation will focus on the older VVER-440/213 and VVER-1000 type plants. Especially the long-term operation of the VVER-440/213 plants requires specific engineering effort.

The VVER-440/230 plants (Kozloduy NPP Bulgaria and Bochunice V1 NPP Slovakia) being already on permanent shutdown will not be considered. In contrast to this the Kola 1 and 2 and Novovoronesh 3 and 4 units in Russia have already received licences to operate for a further fifteen years after implementation of modernisation and safety enhancement programmes (Rosenergoatom, 2003) to cope with the safety issues relevant for this design (IAEA, 1992). The long-term operation and plant lifetime management of VVER-440/230 plant type is not a generic practice and will be discussed below only to a limited extent.

From the point of view of long-term operation, the newly designed and constructed VVER plants are also of less interest. Obviously, they have been designed and manufactured taking into account the aging lessons learned from the operational experience. The question of longer than designed operation of these plants will be and can be considered after decades of operations.

\section{Basic idea of long-term operation}

The safety of nuclear power plants are determined by the functionality and performance of following systems, structures and components (SSCs):

1. Systems structures and components important to safety that perform the basic safety functions i.e.:

a. To ensure integrity of reactor coolant pressure boundary

b. To ensure the capability to shut down the reactor cool-down and maintain it in a safe shutdown condition and

c. To ensure offsite radioactive exposures less than or comparable to limits specified in the national regulations.

2. Structures and components not important to safety but whose failure impacts safety function: The function of a system structure or component may be compromised by failure of a structure or component not important to safety due to different type of interactions.

The SSCs above are classified into safety classes in accordance with national regulation. The classification of SSCs is usually documented in the Final Safety Analysis Report.

During the total operational lifetime, the performance of the SSCs important to safety has to be assured with prescribed margins. The margins are needed for covering the different type of uncertainties of the design, manufacturing and operation and for the assurance that the SSCs will perform their intended safety function even if an accident happen in the last minute of the operation.

The SSCs can be grouped into three main groups according to the possibility of restoration of the function/performance for the compensation of effect of ageing: long-lived passive non-replaceable or not-to-replace structures and components replaceable SSCs and renewable SSCs.

The functionality/performance of all SSCs will be unambiguously decreasing in time due to ageing all of these components. 
The function/performance of the replaceable or renewable SSCs can be restored in proper time, while in case of non-replaceable SSCs the rate of degradation can be influenced via careful operation creation better environmental conditions as that assumed in the design. In some cases, the rate of the degradation can be re-assessed based on new scientific evidences and operational experience. Consequently, the possibility of operation extended over the design lifetime is determined by the ageing and aged condition of long-lived nonreplaceable or not-to-replace structures and components (SCs) relevant for safety like reactor pressure vessel containment etc. The functionality and performance of these SCs limit the operational lifetime.

The assurance of intended safety function of replaceable systems, structures and components is also very important and might be critical. However, the assurance of function and performance of that structures systems and components is mainly question of effort and financing and does not limit the operational lifetime.

Off-course the extension of operational lifetime is a business decision of the owners of the plant. From this point of view, the performance and functionality of SSCs important for production also pose limit in time for the extension of operation. The Fig. 1 illustrates the concept outlined above.

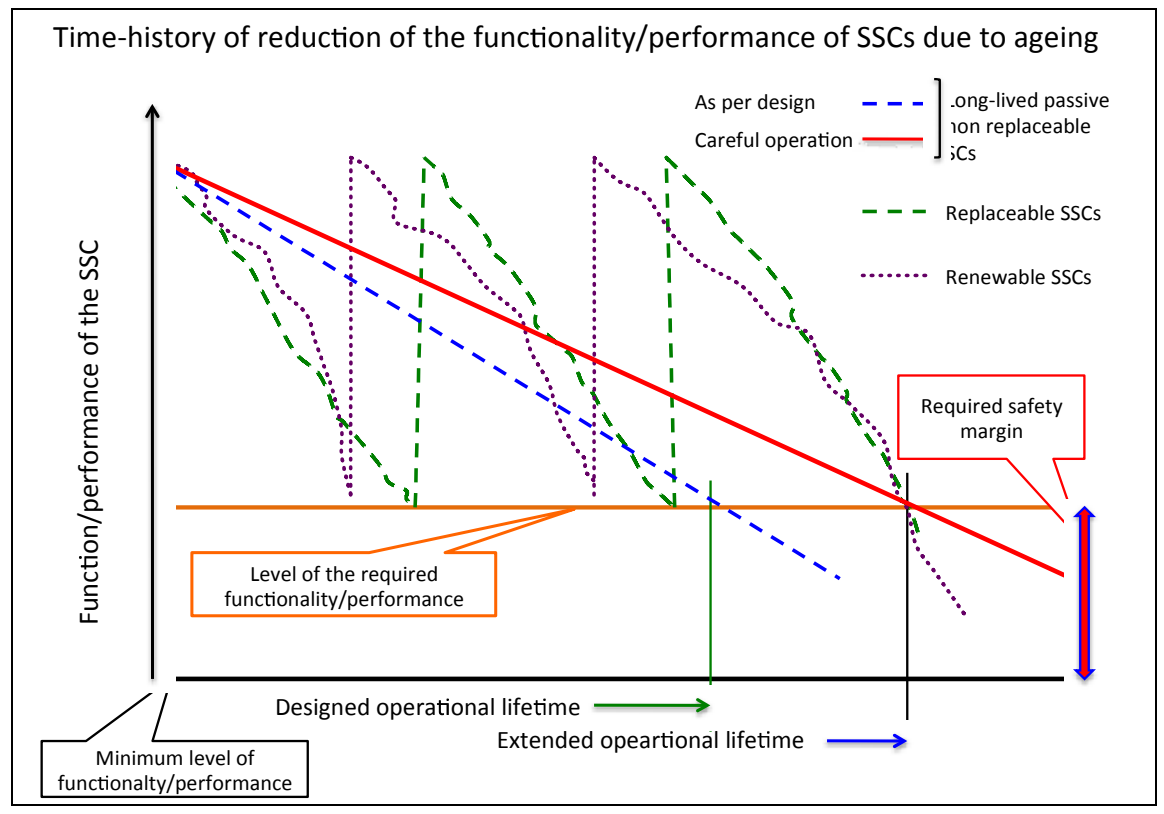

Fig. 1. Why the operational lifetime can be extended?

\section{Basic features of the VVER design}

In the sections below, the basic design characteristics of VVER plants are presented. The design and manufacturing features are also discussed, which are relevant from the point of view of long-term operation (LTO). Safety and compliance with current licensing basis and international requirements are the preconditions for LTO. 


\subsection{The VVER-440 models}

\subsubsection{Basic design features of the VVER-440}

The VVER-440 V-179, V-230 and V-213 plants are equipped with a six-loop VVER-440 reactor. In each loop there are main isolating valves (MIV) on the cold and hot legs, one main circulation pump (MCP) per loop and the horizontal steam generators (SG). The pressurizer with safety valves is connected to the primary loop. The two generations of VVER-440 type reactors have very similar layouts of their primary systems; see Fig. 2. Typical operating parameters are $\mathrm{T}_{\text {hot }}=297^{\circ} \mathrm{C} \mathrm{T}_{\text {cold }}=266^{\circ} \mathrm{C} p=12.3 \mathrm{MPa}$ as it shown in Fig. 3 . The design bases of the two VVER-440 types (i.e. the 230 and the 213) are essentially different. This has consequences in the design of safety systems and confinement.

There are 16 nuclear power plant units of type VVER-440/213 namely: four in Hungary, four in the Czech Republic and four in Slovakia two in Russia and two in Ukraine. The owners of these plants are preparing for long-term operational life of these units.

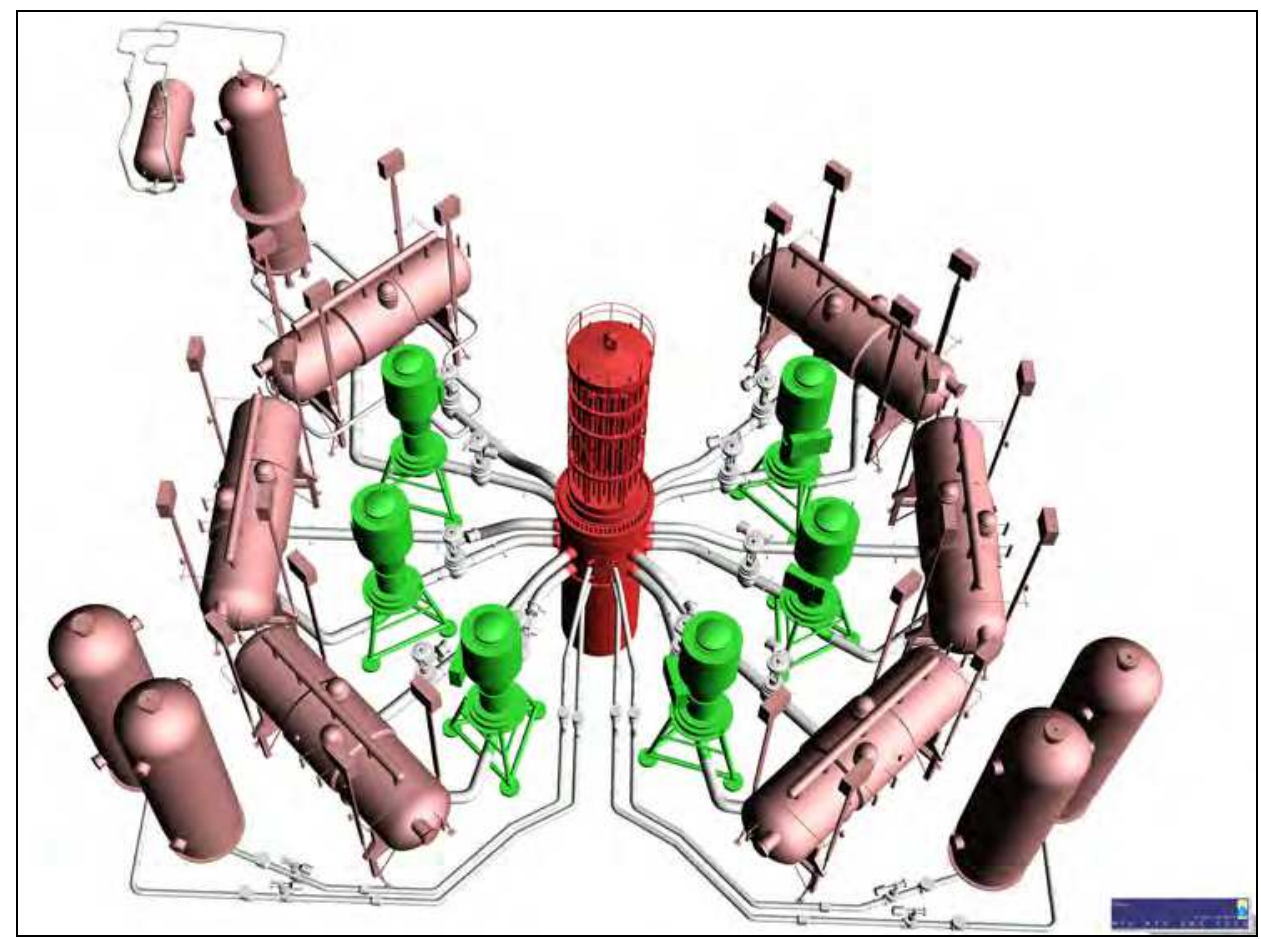

Fig. 2. Layout of the primary system of VVER-440/213 design

The design bases for the VVER-440/213 safety systems are similar to those used in Western PWRs, including the postulating the a double-end guillotine break of the main circulation line in the reactor coolant system. The safety systems exhibit triple redundancy and the reactors have bubbler condenser-type pressure suppression containments capable of withstanding the imposed loads and maintaining containment functionality even following large break LOCA. The VVER-440/213 plants design considered internal and external hazards to some extent. In addition, protection against single failures in the auxiliary and 
safety systems has generally been provided by the design. The safety concerns with VVER$440 / 213$ plants are discussed in detail in an IAEA report (IAEA 1996a).

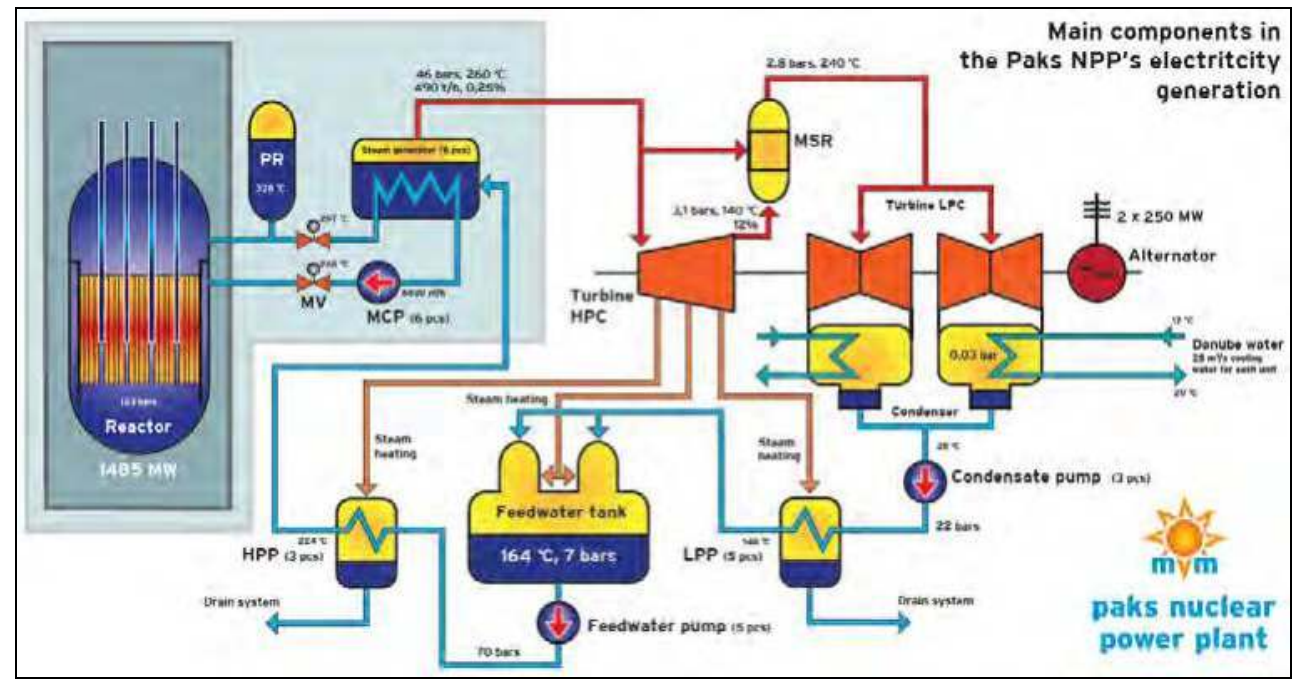

Fig. 3. The technology of VVER-440/213 (Legend: PR-pressurizer, MV-main valve, MCPmain circulation pump, HPP, LPP-high and low pressure preheater and HPC LPC - high and low pressure parts of the turbine respectively)

The VVER-440/213 has essentially inherent safety characteristics e.g. robustness of the design, low heat flux in the core large water inventory in the primary system and a large containment volume, which compensates other deficiencies in the containment concept to a large extent. At all plants, most of the safety deficiencies have been addressed by backfitting and plant modifications. Due to the robust original design it was feasible to upgrade the safety of the original VVER-440/213 design to a level comparable with the PWR plants of the same vintage. At the latest constructed units of VVER-440/213, like the Mochovce NPP units 1 and 2, several improvements and modifications were already made during the design and construction phase.

There are specific modifications of the VVER-440 design: The Finish nuclear power plant at Loviisa represents a combination of the VVER-440/230 basic design and nuclear island equipment with a Westinghouse-type reduced pressure ice-condenser containment and several other western-designed and manufactured systems like the complete instrumentation and control systems (I\&C). These units have very successful operational history and excellent safety features. A comprehensive lifetime management programme was launched in the very early phase of operation, which has allowed long-term operation of the Loviisa units. The Armenian reactor also represents a modification of VVER-440 with an enhanced seismic capacity. It has to be mentioned that the shutdown units 3 and 4 at Kozloduy NPP Bulgaria represent an intermediate type between 230 and 213 series.

It should be noted that the VVER-440s have certain inherent safety characteristics that are superior to most modern PWR plants e.g. robust design large water inventory in the primary system relative to the reactor power large volume of the confinement etc. 


\subsubsection{The VVER-440 features relevant for LTO}

In case of VVER-440 plant designs, the operational lifetime-limiting structures and components are the containment building, the reactor pressure vessel (RPV) and the steam generator (SG). Contrary to the VVER-1000 and PWRs the steam generators are practically not replaceable in case of VVER-440/213 design.

The ferritic-steel reactor pressure vessel is clad internally with austenitic stainless steel. The reactor pressure vessels are made from low alloy steel (15Cr2MVA; Loviisa 12Cr2MFA) the circumferential submerged arc welding was made using Sv-10CrMoVTi wire. The RPV covered internally by welded clad of two stainless steel layers. The inner layer is a nonstabilised stainless steel (Sv-07Cr25Ni13 similar to AISI 309) and that in contact with the coolant is a niobium stabilised stainless steel ( $\mathrm{Sv}-08 \mathrm{Cr} 19 \mathrm{Ni10Mn} 2 \mathrm{Nb}$ (Loviisa Sv07Cr19Ni10 Nb) both equivalent to AISI 347).

From the point of view of longer-term operation, the main deficiency of VVER-440/230 was the high irradiation exposure of the reactor pressure vessel (RPV) wall by fast neutrons and the relatively quick embrittlement of the RPV material. The issue had been aggravated by the lack of a proper RPV surveillance programme at these plants. Several attempts have been made to assess the embrittlement of the base and weld material of those RPVs. For the first generation RPVs essential data for RPV materials, e.g. transition temperature, concentration of copper and phosphorus were absent; archive metal of RPVs was not available. The phosphorus and copper contents in the welds of WWER-440/230 are between $0.030-0.048 \%$ and $0.10-0.18 \%$ respectively. In the case of VVER-440/213 the same concentrations are in the range of $0.010-0.028 \%$ for $\mathrm{P}$ and $0.03-0.18 \%$ for $\mathrm{Cu}$ (Vasiliev\&Kopiev, 2007).

Several measures were implemented for the resolution of the RPV embrittlement issue:

- $\quad$ reduction of the neutron flux on the RPV via low leakage core design dummy shielding assemblies and annealing i.e. affecting the change of material properties

- $\quad$ heating up the water in the emergency core cooling system (ECCS) to lessen thermal shock in a pressurized thermal shock (PTS) situation, steam-line isolation system solutions interlocks, i.e. decreasing the stressors

- introduction of volumetric non-destructive testing for in-service inspection.

Annealing of RPV has been implemented at Loviisa NPP and Kola NPP (also at the shut down plant Buchunice V1). Assessment of annealing effectiveness (level of properties recovering after annealing), determination of re-irradiation re-embrittlement rates after annealing and the behaviour of WWER-440 weld materials showed the real possibilities for recovering RPV toughness properties of irradiated WWER-440 RPV materials. Measures were also taken to improve the knowledge of the vessel material by vessel sampling. Also reducing of neutron irradiation loading of the RPV wall via dummy assemblies around the core was implemented. More detailed description of the RPV neutron irradiation embrittlement issue is provided e.g. in (Erak et al, 2007).

'Extended Surveillance Specimen Programme' was prepared with the aim to validate the results of the standard programme (Kupca, 2006). It was prepared for increasing the accuracy of the neutron fluence measurement, improvement of the determination of the actual temperature of irradiation, fixing the orientation of RPV samples to the centre of the reactor core, minimizing the differences of neutron doses at the Charpy- $\mathrm{V}$ notch and crackopening-displacement specimens and to evaluate any dose rate effects.

For the Mochovce NPP units 1 and 2, a completely new surveillance programme was prepared based on the philosophy that the results of the programme must be available during the whole service life of the NPP. The new advanced surveillance programme deals 
with the irradiation embrittlement of the RPV weld area heat affected zone and the RPV austenitic stainless steel cladding, which were not evaluated until this time in the surveillance programmes.

Reactor pressure vessel surveillance programmes became obligatory in all VVER plants that had been commissioned after Units 1 and 2 at Loviisa.

Proper RPV surveillance programmes have been implemented at VVER-440/213 plants outside of former Soviet Union. Since the PTS (pressure-temperature-loading limits) is the lifetime limiting process for the RPV of VVERs, the methodology of PTS evaluation has to be established in the national regulations, which takes into account the applicable best practices, the features of the RPV and the thermal-hydraulic peculiarities of the VVERs. The assumptions of renewed PTS analyses have been confirmed with mixing tests. The embrittlement of the RPV has been controlled via low-leakage core design. Considering the VVER-440/213 plants, annealing of RPV has been implemented at Rivne NPP.

Components of the primary circuit in contact with the primary coolant other than RPV are also made of austenitic stainless steel, i.e. the piping of the primary loop the main circulating pumps gate valves and the emergency and auxiliary systems pipework.

The steam generators in VVER are horizontal (see Fig.4).

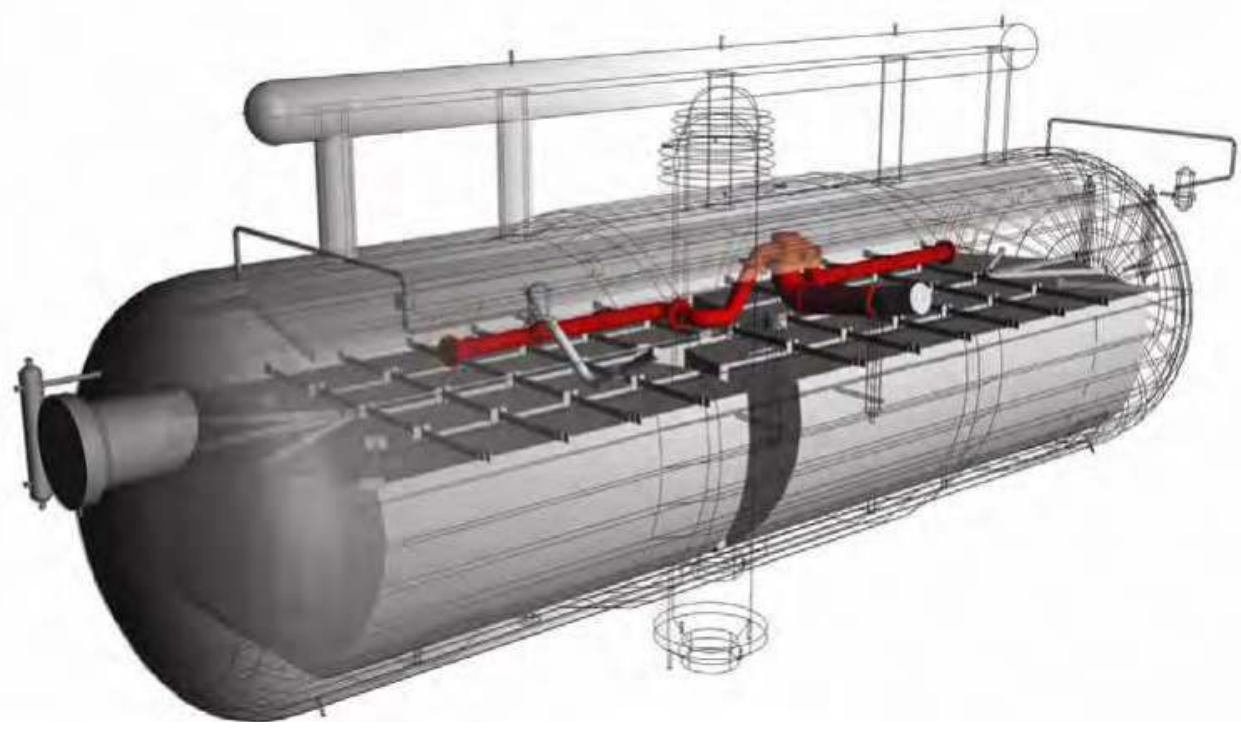

Fig. 4. Steam-generator of VVER-440/213 design

The heat exchanging tubes and the steam generator tube headers (collectors) are manufactured from austenitic stainless steel (18\% Cr $10 \% \mathrm{Ni}$ stabilized with titanium) in VVERs, instead of the nickel-based alloys (Alloy 600 and 690) and higher chromiumcontaining alloys (Alloy 800) used in PWR. The material of the SG heat exchanging tubes in VVER-440 is equivalent to AISI 321. The advantages of the VVER horizontal steam generator design are the high reliability absence of vibrations, no accumulation of sludge at the tube sheet and easy to access for the maintenance. 
The SG design has positive impact on safety as well, e.g. the design allow reliable natural circulation, effective gas removal, large water inventory and essential thickness of the heat exchanging tubes.

The oldest VVER-440 type steam generators at Novovoronesh NPP unit 3 and 4 are operating already 40 years. Condition of the oldest VVER-440 steam generators at Kola and Novovoronesh plant allows 15 years extension of operation of these plants. According to the operational experience, the feed-water distributor inside the SG shows accelerated ageing due to erosion. These elements were replaced practically at all VVER-440 plants (see the red coloured new distributor in Fig.4).

The experience regarding ageing of VVER steam generators is summarised in the report of the International Atomic Energy (IAEA, 2007). At WWER-440 plants, the lifetime limiting ageing mechanism of the SGs is "Outer Diameter Stress Corrosion Cracking (ODSCC)" of the austenitic stainless steel heat-exchanger tubes. The ODSCC indications appear typically $(80 \%)$ at the grid structure supporting the tube bundle where the secondary circuit corrosion products with concentrated corrosive agents are deposited. An eddy-current inspection programme is implemented for monitoring the tubes. Samples have been removed from plugged tubes to facilitate investigations of the phenomena. The rate of ODSCC was essentially slowed down by a series of modifications and actions implemented at different plant to different extent.

The measures implemented are as follows:

- Replacement of the condensers: the new condensers have austenitic stainless steel tubes

- Removal of copper and copper-bearing alloys from the secondary circuit

- $\quad$ Replacement of the feed-water distributor (the old one was manufactured from carbon steel)

- $\quad$ Cleaning the heat exchanging surface of the SGs

- Introducing high $\mathrm{pH}$ secondary water chemistry

- $\quad$ Replacement of the high-pressure pre-heaters (with erosion-corrosion resistant tubes).

All these measures have been implemented at Paks NPP, which completely changes the conditions and the rate of ODSCC in the SGs. Consequently, a better (i.e. decreasing) plugging trend is experienced, which can also be expected in the long-term. The gaps between the tubes and support grid are still the critical places since remaining corrosion products accumulate there. It is therefore difficult to forecast the ODSCC rate in the gaps and the ageing process has to be well monitored in the future. Under the new conditions, sludge may be accumulated at the bottom area of the SG. An effective method for draining the sludge has to be found. The reserve in heat exchanger surfaces of the SG is relative large (more than 15\%). Considering past experience and the recent plugging trend of the heat exchange tubes, none of the SGs would exceed $10 \%$ of plugged tubes by the end of 50 years operation due to implemented measures (Katona et al, 2003); see also (Trunov et al, 2006). The number of allowable plugged tubes became more important at the plant where the primary energy output is increased for the power up-rate. Therefore, establishing adequate performance criteria for the steam generators is very important.

The reduced pressure containment of VVER-440/213 is made of reinforced concrete, and steel liner ensures the leak tightness. Therefore, the basic concern regarding containment ageing is the affect of ageing on the containment leak-tightness. The leak rates of VVER$440 / 213$ containment allowed by the design and justified by the regular integral tests equals to $14.7 \%$ /day at the post large-break loss-of-coolant accident when the design internal containment pressure equals $2.4 \mathrm{MPa}$. It is clearly higher at some plants than is allowed for 
Western NPP containments. Therefore, the goal of the VVER operators is to improve the leak-tightness. (It should be noted that comparison with Western NPP containments could not be straightforward. In case of design basis accidents the pressure suppression system tends to cause an under-atmospheric pressure rather than overpressure at the time period when the atmosphere of the containment has its highest contents of radioactive aerosols and when the potential for radioactive releases would thus be the highest.) Containment leakage has a complex origin. Investigations carried out at Paks and Buchunice NPP practically from the time of start-up tests shows that the poor sealing of doors and hatches mainly cause the containment leakage. It means that the leakage itself is a maintenance problem rather than an ageing issue.

Some VVER plants are built on relatively soft soil. Geodetic control of the settlement of main building of these plants was started during the construction and it is periodically performed. The phenomena might be a concern when the uneven settlement, i.e. the differential movement causes unaccepted additional deformation of the structures. Experience shows that the differential movement may cause cracks in non-structural masonry walls. Other concern might be, if the non-uniform settlement results in non-allowed tilting of the RPV vertical axis, which would cause problems for control rod drive mechanisms (CRDMs). The operating experience and analysis of settlement with extrapolation to extended operational lifetime is discussed for Paks NPP in (Katona et al, 2009a).

As per operational experience, ageing of both reinforced concrete load bearing structure and liner do not limit the long-term operation of the VVER-440/213 plants.

\subsection{VVER-1000 model}

\subsubsection{Basic design features of the VVER-1000}

The VVER-1000 model exists in several versions. The "small series" plants could be considered as pioneers of this model. The VVER-1000/320 is the large series version of the design. The VVER-1000/320 type plants are operated in Bulgaria, Czech Republic, Russia, Ukraine and China: they were developed after 1975. Modernised versions of VVER-1000 plants are under construction in five countries (Bulgaria, China, India, Iran and Russia).

Regarding lifetime management, the VVER-1000/320 plants have practical importance. The "small series" plants show some specific design features however the lifetime management practice of these plants does not differ essentially from those in the case of the VVER$1000 / 320$ version.

The VVER-1000 is a four loop PWR with horizontal steam generators. Each loop consists of a hot leg, a horizontal steam generator, a main circulating pump and a cold leg. Main isolating valves on the hot and cold legs of each loop equip the non-standard VVER-1000 primary loops. The standard V-320 design and the new clones of the VVER-1000 do not have isolating valves on the primary loops. A pressuriser is connected to the hot leg of one of the loops and the spray line to the cold leg. Operating conditions are $\mathrm{T}_{\text {hot }}=322^{\circ} \mathrm{C} \mathrm{T}_{\text {cold }}=290^{\circ} \mathrm{C}$ $\mathrm{p}=15.7 \mathrm{MPa}$.

The reactor, the primary and safety systems are all placed within a full pressure, dry, prestressed concrete containment.

The design bases and the technical solutions applied are very similar to the PWRs operated in Western countries. The safety concerns about the VVER-1000 plants are discussed in detail in IAEA reports; see (IAEA, 1996b) and (IAEA, 2000). The main safety concern regarding the VVER-1000 plants lies in the quality and reliability of the individual equipment especially the instrumentation and control (I\&C) equipment. The plant layout 
has weaknesses that make the redundant system parts vulnerable to hazardous systems interactions and common cause failures caused by fires internal floods or external hazards. At all plants, many of these deficiencies have been addressed by plant modifications and an acceptable safety level has thus been achieved.

There are several advanced VVER-1000 plants presently under construction and more than 20 new projects of advanced VVER design are under preparation or consideration and several are in the bidding phase. The most advanced versions of VVER design showing features of Generation III reactors are considered for future bids for large generating capacity reactors.

\subsubsection{Features of VVER-1000 model relevant for LTO}

In case of VVER-1000, the proven design solutions of VVER-440 are implemented like the horizontal steam generator also the concept of the material selection. In the VVER-1000 models, all primary circuit surfaces either are made from or are clad in stainless steel. The 08X18H10T type stainless steel (08Cr18Ni10Ti AISI 321) is used for the core structures, main circulating pumps and steam generator tubing, whilst the main loop pipework and steam generator collectors are manufactured from 10GN2MFA type carbon steel and the cladding is made from 08Cr18Ni10T stainless steel. The pressuriser is also made from 10GN2MFA carbon steel covered by cladding with an inner layer of Sv-07Cr25Ni13 (similar to AISI 309) stainless steel and two layers of Sv-08Cr19Ni10Mn2Nb niobium stabilised stainless steel (similar to AISI 347). The reactor pressure vessel and head are made from the low alloy steel 15Cr2MNFA. The cladding of the reactor head has an inner layer of Sv-07Cr25Ni13 stainless steel and two layers of the niobium stabilised stainless steel Sv-04Cr20Ni10Mn2Nb (again similar to AISI 347). The phosphorus and copper contents in the welds of WWER-1000 are $0.005-0.014 \%$ and $0.03-0.08 \%$ respectively. The quality of manufacturing and alloy composition ensure the possibility of LTO for VVER-1000 reactors (Vasiliev\&Kopiev, 2007].

For newly commissioned WWER-1000 plants and plants in construction, essential modifications of the surveillance programme have been implemented. Specimen containers are located in positions representative for vessel wall conditions at Temelin NPP. Based on the fracture mechanics analysis, it was recommended to heat up the accumulator water to $55^{\circ} \mathrm{C}$ and to prevent injection of ECCS water with temperatures below $20^{\circ} \mathrm{C}$ for all the plants. The use of low neutron leakage core loading patterns in WWER-1000 reactors reduces the RPV wall fluences by approximately $30 \%$. It was planned to introduce partial low leakage loading patterns at some plants during 1994 (i.e. fuel assemblies with high burn-up to be placed at the core periphery).

The steam generators for VVER-1000 have been designed on the same principles as in case of VVER-440 plants. However, the SGs at VVER-1000 plants are replaceable.

At some Units throughout the design service life of SG there were problems resulting in necessity of SG replacement.

At the same time, the SGs at some plants can be operated above design service life. As the operating experience shows, the water chemistry of the secondary circuit is the main factor influencing operability of the SG tubing like in the case of VVER-440 plants.

Tube integrity is inspected by eddy current method. The results of eddy current test can be used to determine the plugging criterion for defected tubes. Proper definition of the plugging criterion was an important problem.

The ageing problems of the SGs at VVER-1000 plants are as follows; see (Trunov et al, 2006): 
- cracking at headers of the cold collectors of the heat-exchanging tubes

- degradation of the welded zone at hot collector headers

- $\quad$ corrosion of the heat-exchanging tubes

- $\quad$ formation of deposits

- difficulties in measuring and regulating the SG water level.

A study performed in the frame of the International Atomic Energy Agency summarises the status of knowledge on the steam generator ageing (IAEA, 2007).

In VVER-1000 plants, ageing may affect the pre-stressing of the containment. Important ageing mechanisms of the pre-stressed containment and its structural elements, e.g. the tendons anchorages are the relaxation shrinkage creep of steel resulting in loss of pre-stress. Requirements on testing of containment pre-stressing system are defined both by the designer and regulation (Orgenergostroy, 1989a) and (Orgenergostroy, 1989a). The scope of inspection shall be extended if defects are observed and/or average loss of tension force is more than $15 \%$. If additional control verifies obtained results, it is necessary to test $100 \%$ of tendons. Tendons with force losses more $15 \%$ shall be once again controlled after straining. In the case if a force loss at 24 hours is more than $10 \%$ the tendon shall be replaced. In order to enable monitoring of the level of the containment pre-stressing measurement systems are installed permanently on the structure and these systems measure structure deformations and pre-stressing force in the cables.

At VVER-1000 plants, detailed field investigations and analyses have been carried out for the assessment and evaluation of the condition of pre-stressing tendons. There are design solutions for the replacement of tendons. Thus, all existing defects leading to loss of stressing force and rupture of tendons have been avoided.

At some plants, new pre-stressing system and an additional system for automatic control of stressing forces is installed in the bundles.

\section{Feasibility of long-term operation}

\subsection{Preconditions and motivations for long-tem operation}

Pioneers of the extension of operational lifetime were the VVER-440/213 operators. It was already recognised in 1992 that the favourable characteristics of the VVER-440/213 plants, the comprehensive safety enhancing programme launched and partially already implemented by the operating companies, the operational and maintenance practice of the operator give an opportunity to extend the operation lifetime (Katona\&Bajsz, 1992).

Decision on the preparation of feasibility studies for LTO had been based on the recognition of the following VVER features and experiences:

- $\quad$ robust design of VVER-440/213 design

- good plant condition due to well-developed maintenance in-service inspections, careful operation and extensive modernisation and reconstructions

- $\quad$ successful implementation of safety upgrading measures resulting in acceptable level of safety.

Safety of the plants and compliance with international standards have been generally considered as decisive preconditions for long-term operation.

The comprehensive modernisation and safety upgrading programmes implemented by the VVER operators during last two decades resulted in gradual decreasing of the core damage frequency (CDF) of these plants. For example, the level 1 Probabilistic Safety Analysis (PSA) study establishes the resulting CDF for all units at Dukovany NPP between $1.47 \div 1.67^{*} 10^{-5} / \mathrm{a}$ 
(Czech Report, 2010). The same achievements are published for other VVER plants in the national reports compiled under Safety Convention; see (Slovak Report, 2010). The CDF for Bochunice V-2 NPP is shown in Fig. 5.

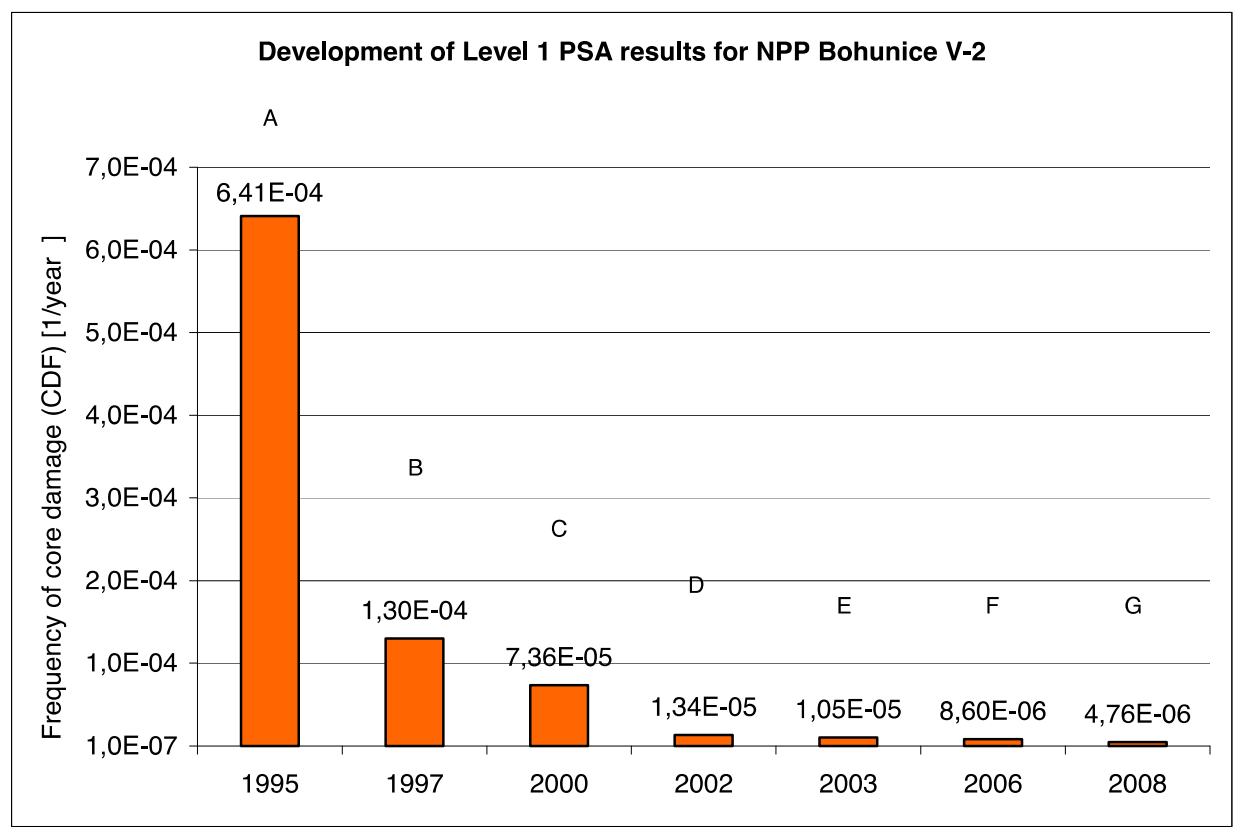

Fig. 5. Decreasing the CDF for Bochunice V-2 NPP due to the implementation of safety upgrading measures (Slovak Report, 2010)

Similar to Slovak and Czech plants results have been achieved at Paks NPP in Hungary too. Extensive modernisation and safety upgrading programme has been implemented in Ukraine (Ukraine, 2011) and Russia (Rosenergoatom, 2003) and Bulgaria (Popov, 2007) too. One of the issues related to the justification of the compliance with current licensing basis at VVERs operated outside of Russia is the lack of the knowledge of design basis, especially the assumptions made by the designer with respect to the ageing mechanisms, stressors and time limits of the safe operation of the components.

The availability of design base information is a current licensing basis requirement. In the same time knowledge of design base is unavoidable for the preparation of long-term operation and licence renewal especially for the review of time-limited ageing analyses.

Operators of WWER-440/213 units have to perform specific project for the design base reconstitution. The design base reconstitution covers the identification of design base functions values and bounding conditions according to the licensing basis.

Two basic tasks have to be performed while reconstituting the design base:

- collection and review the original design information

- consideration of the changes of the licensing basis since the design and issuance of the operational licence.

The design of VVER-440/213 and the older VVER-1000 plants was generally based on the former USSR regulations of early the seventies: 
- General Requirements on Safety of NPP Design, Construction and Operation (OPB- 73) and

- $\quad$ General Safety Rules for Atomic Power Plants (PBYa -74).

OPB-73 marked the beginning of a transition to the generally accepted international practice in nuclear safety (e.g. defence in depth, single failure criterion).

Additional work was needed for the proper definition of design base values and conditions. Design input loads and conditions had to be newly defined for the most important SSC. Information sources for this work were:

- $\quad$ the existing design information

- $\quad$ results of the periodic safety reviews

- current licensing basis compliance check

- transient analyses newly performed for the final safety analysis reports (FSAR)

- operation history.

The design base has to be newly created taking into account all essential changes in the licensing basis. For example, in case of Paks NPP seismic loads were not considered in the design. Current design/licencing base includes safe shutdown earthquake with $0.25 \mathrm{~g}$ horizontal acceleration.

The good plant condition and appropriate plant programmes are also preconditions for long-term operations. Especially the surveillance of the RPV embrittlement and monitoring of the condition of long-lived passive structures and components are of interest. The most important ageing management (AM) activities are performed at the VVER plants from the very beginning of the operation. The early AM activity was focused on the known degradation of main SSCs like reactor pressure vessel (RPV) embrittlement or on issue cases, e.g. leaking of the confinement due to the liner degradation outer surface corrosion of the steam generator heat-exchange tubes. Most of early AM programmes were state-of-the-art as for example the RPV surveillance programme. In the course of the first periodic safety reviews, the scope of most critical for operational lifetime SSCs and the dominating ageing mechanisms were defined.

Adequate assessment of the aged condition and forecast of safe lifetime of SCs can only be performed if the ageing process is monitored properly from the very beginning of the operation. The operational history of SCs has to be documented in sufficient details for performing the trending.

Availability of a state-of-the-art FSAR and its regular updating is required for the control of compliance with CLB and configuration management.

The national regulation allowing the approval of the prolongation of the operation beyond designed operational lifetime is also and unambiguous condition of the long-term operation. The legislative framework of regulatory approval of long-term operation in the VVER operating countries is based either on the periodic safety review or on the formal licence renewal.

There are several non-technical conditions, which affected the strategy of VVER operators and motivated the decision on LTO. The positive international tendencies with regard to long-term operation of existing nuclear power generation capacities stimulate the LTO of VVERs too. (This tendency might be changed by the nuclear accident following the Great Tohuku earthquake in Japan March 2011.) Accumulation of the experiences and scientific evidences for justification of longer than designed operation of NPPs provides good basis also for LTO of the VVER. Good market positions of NPPs overall in the VVER operating countries and high level of public acceptance and positive public attitude towards operation of NPPs in these countries. 
The intention to prolong the operational lifetime of existing NPPs was also motivated by very low probability for the extension of nuclear power capacity in late nineties since all trials for launching new nuclear projects failed and several projects have been stopped and frozen already for long time.

\subsection{The feasibility study}

The main goal of the feasibility studies was the preparation of the final owners decision regarding LTO and licence renewal. Simultaneously, the authorities in the VVER operating countries started the preparation of regulations on long-term operation and licencing.

According to (Katona et al, 2001) the feasibility was checked from technical and safety point of view via:

- $\quad$ assessment of plant safety and overall technical condition

- forecast for the lifetime expectations of non-replaceable structures and components

- assessment of the effectiveness of the plant operational and maintenance practice

- evaluation of the safety level of the plant and forecast for the extent of future safety upgrading measures based on the international tendencies in the $R \& D$ and development of regulations

- effort needed for ensuring the safety and operational performance scheduled replacements reconstructions

Logic followed in the feasibility study is shown in Fig.6.

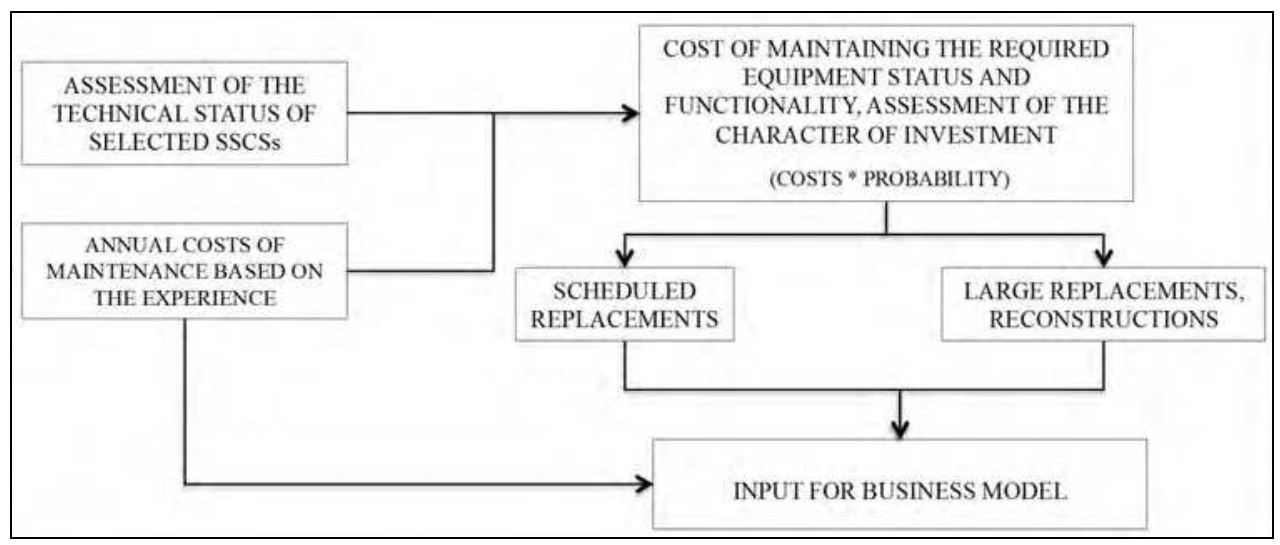

Fig. 6. Logic followed in the feasibility study

It has been found that there is no technical or safety limitation to the 50 years of operation of the Paks NPP. In case of most systems and equipment, the monitoring maintenance and regular renewal practice of the plant allows for the lifetime extension without outstanding costs. There is a well defined number of SSCs only, which require extensive reconstruction and investment as the possibility of compensating for the effects of ageing is limited or a significant moral ageing can be expected. In case of some SSCs, capacity expansion might be needed (e.g. radioactive waste storage tanks).

Findings related to the reactor vessels and steam generators had been dealt with specific attention since these are in case of VVER-440/213 the real lifetime limiting components. As for the reactor vessels of VVER-440/213 at Paks NPP, the embrittlement due to fast neutron 
irradiation of the reactor pressure vessels material was found the dominant ageing process. The condition of the RPV was different at different plants. While performing the feasibility study, the condition of RPV at Paks NPP was found that the RPVs of Unit 3 and 4 could be operated without extra measures even at 50 years. It was found that the water in the emergency core cooling (ECC) tanks should be heated up in order to decrease stress levels caused by pressurized thermal shock (PTS) transients. For this purpose, cost-effective technical solutions were already available. At Unit 1 in case of the 50-year lifetime in addition to the ECC heating-up the annealing of the welded joint No. 5/6 close to the core had been considered with $50 \%$ probability. It has to be mentioned that these conclusions were revised later on the basis of more sophisticated analyses.

In case of VVER-440/213, the steam generators are not replaceable in a practically reasonable way. Therefore, the steam generators are as critical as the reactor pressure vessels from the point of view of lifetime limits of the safe operation of the plant. A forecast of the expected change of the steam generator performance has to be made based on the plugging rate.

In case of VVER-1000, the reactor pressure vessel and the containment are the real lifetime limiting SCs since the steam-generator is replaceable.

Simultaneously with the assessment of the plant condition and lifetime expectations of the most important non-replaceable structures and components, the evaluation of the effort of the scheduled replacements, safety upgrading measures and reconstructions the costs for maintaining the required plant condition and sustaining the capability of operating company had to be assessed. These data had been used for input of business evaluation of the LTO. Simplified presentation of the business model is shown in Fig.7. Several options might be been investigated: $0,10,20$ and 30 years of prolongation of operation beyond the licenced 30 years. The results of the study determined the objective of the PLiM.

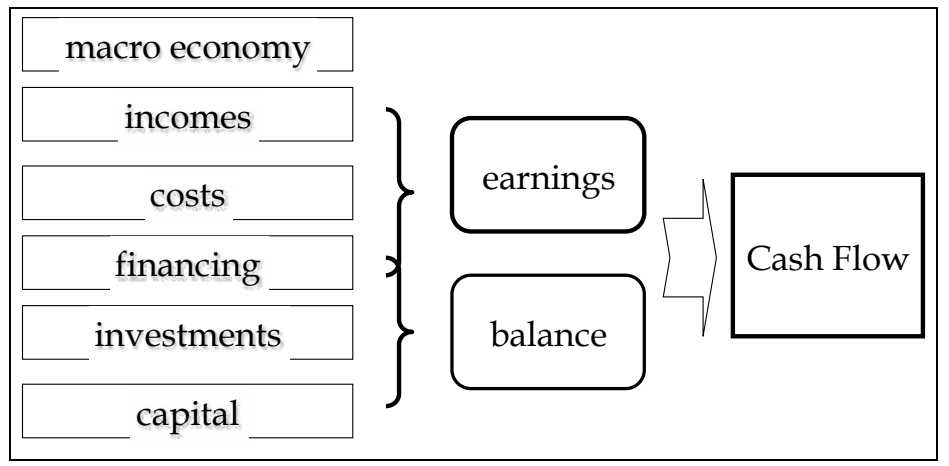

Fig. 7. The business model

Similar to the study presented above has been made for Dukovany NPP in the Czech Republic (Kadecka, 2007) and (Kadecka, 2009).

\subsection{Synergy between long-term operation and safety upgrading and modernisations}

There is a synergy between the long-term operation and different plant actions and measures implemented for safety upgrading, power up-rate, improving reliability and plant programmes. This will be shown below based on (Katona, 2006). 
Implementation of the safety-upgrading programme for ensuring the compliance with national and international requirements is a precondition for LTO. In the same time, the safety is the most important aspect of public acceptance. The operator commitment in relation of safety is and will be the decisive point of judgement of the public.

Most of the safety upgrading measures results in positive technical effect too. Due to these modifications, the safety systems or their essential parts had been practically renewed, reconstructed. Consequently, large part of safety systems is not aged. In some cases, safetyupgrading measures have direct influence on the lifetime limiting processes. For example, the new relief valves installed on the pressurizer for the cold over-pressurisation protection eliminate the danger of brittle fracture of the reactor vessel.

Some of the VVER plants implemented extensive seismic upgrading programme involving addition of large number of new seismic fixes and other strengthening measures; see papers in (IAEA, 1993). Fixing the building structures, the anchorages equipment, cabinets and racks, also the structural support of cable trays can be considered as reconstruction of these SCs.

The most important economical condition for long-term operation is the preserving of the present cost advantage of nuclear electricity generation within the market conditions. Exploiting reserves and advantageous features of the VVER-440/213 reactors the electrical output of the plants can be safely increased up-to approximately 500 MWe by improvement of the efficiency of the secondary circuit/turbine and increasing reactor thermal power via implementation of modernised fuel assemblies. Obviously, the power up-rate should not result in a decrease of the plant safety level and should not cause stressors of ageing which affect the lifetime extension perspectives and the plant availability.

The frequently criticised obsolete I\&C systems were replaced at VVER plants. The new I\&C systems have proper environmental qualification. Beside of the obsolescence, the lack of environmental qualification was the basic issue in case of the old systems practically at all plants.

The major causes of the steam generator heat exchange tube local corrosion is the high concentration level of corrosion activators (chloride ions, sulphates, copper oxides etc.) in the secondary circuit and in the hidden surfaces at the secondary side of the SGs. This is critical in case of VVER-440 hence the steam generators are practically not replaceable. For limitation of the local corrosion, the high level of deposition on the tube surfaces should be eliminated. Most important measure implemented was the replacement the main turbine condenser for example at Paks NPP (Katona et al, 2005). Contrary to the old condensers with copper alloy tube bundle, the new condensers with stainless steel tubing allowed the introduction of the high $\mathrm{pH}$ water regime in the secondary circuit providing better operational condition for components of the feed water system and for the generators as well.

\section{System for ensuring long-term operation}

\subsection{Concept for ensuring longer term operation}

Safe and economically reasonable prolongation of operation of VVER type plants (and any other old vintage plant) should be not limited to the formal regulatory or re-licensing aspects; it has to be considered in broader context (Katona\&Rátkai, 2008) and (Katona et al, 2009). It requires a comprehensive engineering practice, which integrates

- $\quad$ up-to date knowledge on aging phenomena 
- $\quad$ vigilance through condition monitoring / aging management

- $\quad$ ability to recognize the unexpected phenomenon when it arises

- a consequent application of best practices

- feedback of experiences

- $\quad$ proper consideration of VVER-440/V213 features

- graded approach in accordance with safety relevance and plant lifetime limiting character of the given structure/component and ageing process;

A comprehensive plant approach to LTO means:

- All systems, structures and components have to be covered by certain plant programme (ageing management preventive maintenance scheduled replacement etc.). In case of safety classified SSCs, plant programmes and practice should comply with regulation; in case of non safety classified one, the complexity of programme depend on the importance of SSCs regarding power production, e.g. preventive maintenance and in some cases even run to failure concept might be applied.

- All ageing processes have to be considered.

- All plant activities have to be considered i.e. the routine activities should be integrated with those specific to LTO utilizing the synergy between them.

The concept is illustrated in Fig.8.

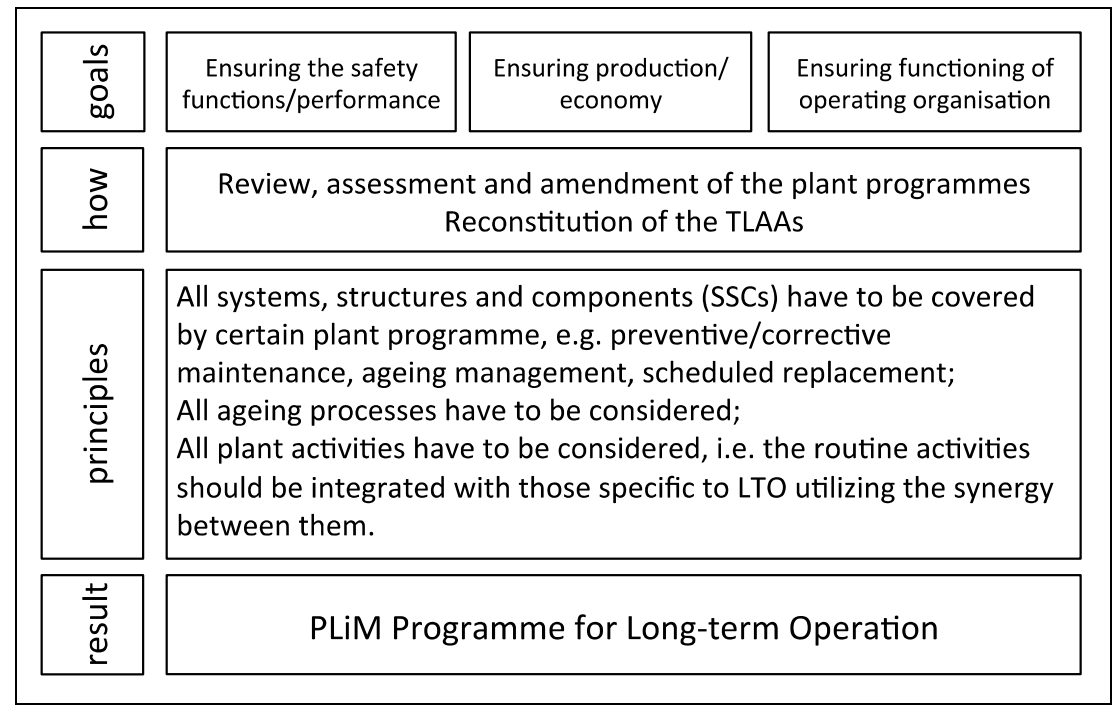

Fig. 8. Concept for preparation of the LTO and LR

\subsection{Scope of systems structures and components to be considered in LTO}

Plant Lifetime Management (PLiM) is complex programme for ensuring safe and long-term production of electrical energy. The scope of LTO should cover the SSCs relevant to safety SSCs important for production and conditions for functioning of operational organisation. PLiM is focusing on ageing on the economically optimal way of ensuring required condition of the plant while ensuring the safety. Practically all SSCs of the plants are within the scope of the PLiM. However, these components can be divided into two categories: 
Category 1 - long-lived non-replaceable components as well as those which replacement will makes the LTO economically not reasonable. These components are the RPV, SG, Main Coolant Pump, main circulation pipeline containment cables and most of the buildings etc. The required condition of these SCs is ensured via ageing management or justified by time limited ageing analyses and environmental qualification validated for the extended time of operation. The method for scoping and screening for ageing management is presented in Section 7.1.

Category 2 - includes all SSCs except for those of Category 1. The required condition of these SSCs is ensured via plant maintenance and scheduled replacement programmes.

The scope of PLiM for LTO is broader than the scope for justification of the safety of the long-term operation developed for obtaining the regulators approval. The regulatory review and approval is focusing on the safety related SSCs and on the plant programmes for ensuring their functioning and performance over the extended operational lifetime. The scope of regulatory approval is presented in the sections below.

\subsection{Methods for ensuring required functionality/performance 5.3.1 The system for ensuring required plant condition}

The control of performance and safety functions shall be ensured by certain plant programme or justified by analysis. The system is illustrated in Fig.9 based on Hungarian Regulatory Guide 4.12; see (Katona, 2010).

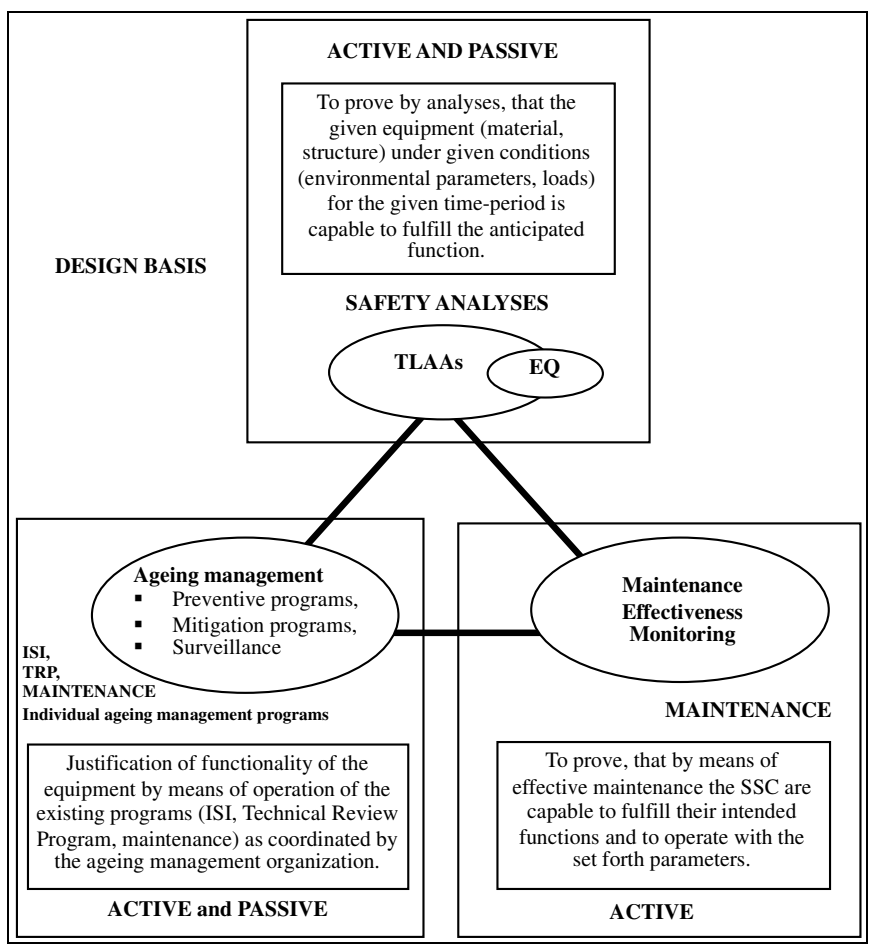

Fig. 9. System for ensuring required safety function and performance of the plant 
The possible plant programmes are the ageing management programmes, routine plant surveillance, in-service inspection, testing and monitoring programmes, the maintenance programmes and the scheduled replacement and reconstruction programmes.

Routine plant programmes can be credited after review and justification of effectiveness.

The criteria of adequacy of existing plant programmes with regard to LTO are presented in Section 7.

The adequacy of TLAAs has to be reviewed and demonstrated while entering into LTO; see section 8 .

Usually, ageing management programmes ensure the performance and function of passive long-lived SCs. Some VVER operators, such as Hungary, ageing management deals with passive components and structures only, since the active components and systems are addressed by the maintenance rule. There are VVER operating countries where the ageing management deals with both active and passive components and structures.

Plant may select and optimise the methods applied for particular SSCs while the plant practice should be gapless, i.e. all SSCs and degradation mechanisms affecting the safety functions should be covered by the system. However, in case of structures and components of high safety relevance, regulation requires performance of dedicated ageing management programmes. In case of systems working in harsh environment, dedicated programme for maintaining of environmental qualification is required.

\subsubsection{Environmental qualification}

Performance and functioning of active systems can be tested during the operation and can be ensured via maintenance under maintenance rule (MR), i.e. evaluation and assessment of the effectiveness of the maintenance along safety criteria and/or via implementation of the programme for maintaining the environmental qualification (EQ).

Environmental qualification should be implemented especially for I\&C equipment, which shall operate in harsh environment.

When the older VVER-440 and VVER-1000 NPPs were built, large part of the originally installed electrical and I\&C equipment did not have initial qualification or the qualification was not certified properly. The issue was recognised already in the first reviews for safety; see (IAEA, 1992) (IAEA, 1996a) (IAEA, 1996b) and (IAEA, 2000).

The resolution of the issue can be made in two steps:

- restoring the initial qualification

- maintaining the qualified condition of the equipment.

The maintenance of the qualification means:

1. Control of the capability of equipment to fulfil its safety function through:

a. periodic testing of systems and components

b. testing of the equipment following maintenance

c. results of service routes by maintenance personnel

d. diagnostics measurements;

2. Development and implementation of scheduled replacement programme taking into account the requirements for environmental qualification while purchasing the new equipment;

3. Preventive maintenance of the equipment;

The environmental qualification should be reviewed and validated for the extended operational lifetime. There are different possible outcomes of the review:

- The qualification remains valid for the period of long-term operation. 
- The qualification has been projected to the end of the period of long-term operation.

- The effects of ageing on the intended function(s) have to be adequately managed for the period of long-term operation via introducing new ageing management programme.

- There is a need for replacement of the equipment.

The plant activity regarding the environmental qualification is a specific TLAA review and revalidation task.

\subsubsection{Maintenance}

According to the logic outlined above, the required condition and functioning of (mainly) active systems and components can be ensured via maintenance or programme for maintaining environmental qualification and/or condition-dependent scheduled replacements.

The plant maintenance programme can be credited as adequate tool for ensuring long-term operation after reviewing and justification of its effectiveness.

Proper procedure has to be in place for monitoring the effectiveness of the maintenance. The monitoring shall demonstrate that the performed maintenance activity ensures the meeting of maintenance objectives set for the SSCs in scope of the maintenance programme and shall provide the necessary information for the improvement of the programme if deviations are detected.

The procedure for monitoring the effectiveness of maintenance should be applied using graded approach depending on the risk-relevance of the SSCs. The risk significance has been defined quantitatively by probabilistic safety analysis (PSA) or qualitatively by expert judgement.

Beyond identification and repair of actual and possible failures, the maintenance process includes other support activities such as in-service inspection and testing, evaluation of maintenance results and monitoring of meeting the maintenance criteria.

These criteria or objectives of the maintenance can be the following:

- Availability

- $\quad$ Success of starting tests

- Failure frequency experienced during tests

- Opening-closing time closing compactness

- Quantity of delivered medium delivery head deviation from the recorded characteristic

- $\quad$ Failure frequency

- Measurement and operation accuracy

- $\quad$ Success of overloading tests

- $\quad$ Repetitive failures that can be prevented by maintenance

- Violation of the Technical Limits and Specifications or being under its effect.

In some countries, e.g. in Hungary the maintenance effectiveness monitoring (MEM) is an adaptation of 10CFR50.65 for the WWER-440/213 design features and Hungarian regulatory environment and plant practice (Katona\&Rátkai 2010). There are two basic methods applied in the monitoring:

- deterministic method, i.e. control of maintenance via testing/measuring performance parameters of component

- probabilistic method, i.e. assessing the effectiveness of maintenance via comparison of reliability/availability parameters on the level of component/system or plant.

Performance parameters are defined in accordance with safety class and risk significance. 
The deterministic method is based on ASME OM Code. For example, in case of pumps the performance criteria to be checked are the head flow-rate and vibration level. Plant level deterministic performance parameters are for example the capacity factor thermal efficiency of the unit leakage of the containment (\%/day).

Risk significance and the probabilistic performance criteria are set based on PSA. Those SSCs are high risk significant, which are in $90 \%$ cut set having high contribution to core damage frequency (CDF) or high Fussel-Vessely rank. Performance criteria are based on the reliability/unavailability of performing safety function. System level performance parameters are for example failure rates per demand (failure/start) or run failure rate (failure/time) during operation. Plant level performance parameters are the CDF or some selected contributors to the CDF and other safety factors (unplanned reactor scrams or safety system actuations per year).

The MEM is under implementation at Paks NPP. For the implementation of ASME OM Code, the existing in-service and post-maintenance testing programmes of the Paks NPP have to be modified and amended. Probabilistic performance criteria are under development now. It is expected that the MEM will improve the safety factors and capacity factors for the plant while the maintenance effort will be optimal. MEM is a prerequisite for license renewal in Hungary since it provides the assurance for the functioning of active components.

\subsection{Regulatory requirements regarding justification and approval of LTO}

Generally, PLiM is not regulated in VVER operated countries. However, the effectiveness of ensuring the safety functions and plant performance is subject of periodical safety reviews.

Contrary to PliM, the long-term operation beyond the originally licensed or designed term needs well-defined justification and regulatory approval; see e.g. (Svab, 2007).

According to (OECD NEA, 2006) and (IAEA, 2006) there are two principal regulatory approaches to LTO depending on the legislation regarding the operational licence.

The operational licence in VVER operating countries is either limited or unlimited in time.

In those countries where the operational licence has a limited validity in time formal renewal of the operational licence is needed. These are Russia and Hungary where the operational licence is limited to the design lifetime namely 30 years. In these countries, the regulation prescribes the conditions for licence renewal.

In Hungary, the national rules for licence renewal have been developed based on the U.S. Nuclear Regulatory Commission licence renewal rule. In Russia, the rules defined within the context with national regulation.

The control of the compliance with current licensing basis can be maintained via

- $\quad$ Final Safety Analysis Report (FSAR) and its annual update

- Periodic Safety Review (PSR) every ten years

- $\quad$ other regulatory tools including Maintenance Rule (MR) inspections etc.

Within the frames of the Periodic Safety Report:

a. It shall be certified that the technical conditions of the buildings and equipment of the unit as well as the standard and conditions of operation fulfil the safety requirements and the contents of the regulatory licence;

b. The current condition of the plant shall be assessed considering the ageing of the SSCs as well as all internal and external factors that influence the safe operation of the facility in the future; 
c. The current characteristics of the plant shall be compared with the regulations considered as up-to-date in international practice and the deviations limiting the safe operability shall be defined according to the regulations considered as up-to-date;

d. The risk factors revealed based on Items b) and c) shall be ranked and a corrective action program shall be created in order to increase the level of safety.

If the PSR is the basis of the approval for LTO it has to have an extended scope compared to the previous PSR.

The PSR for approving LTO has to include the following tasks:

- comprehensive assessment of the condition of the plant

- $\quad$ review of the plant programmes especially the ageing management activity and

- revalidation of time-limiting ageing analyses for safety relevant long-lived and passive SCs.

The LR is focusing on the ageing of the long-lived passive SCs and revalidation of TLAAs while the performance of active systems and components is controlled in accordance to the maintenance rule and via programmes for maintaining the environmental qualification.

The logic of the justification of the application is shown in Fig.10.

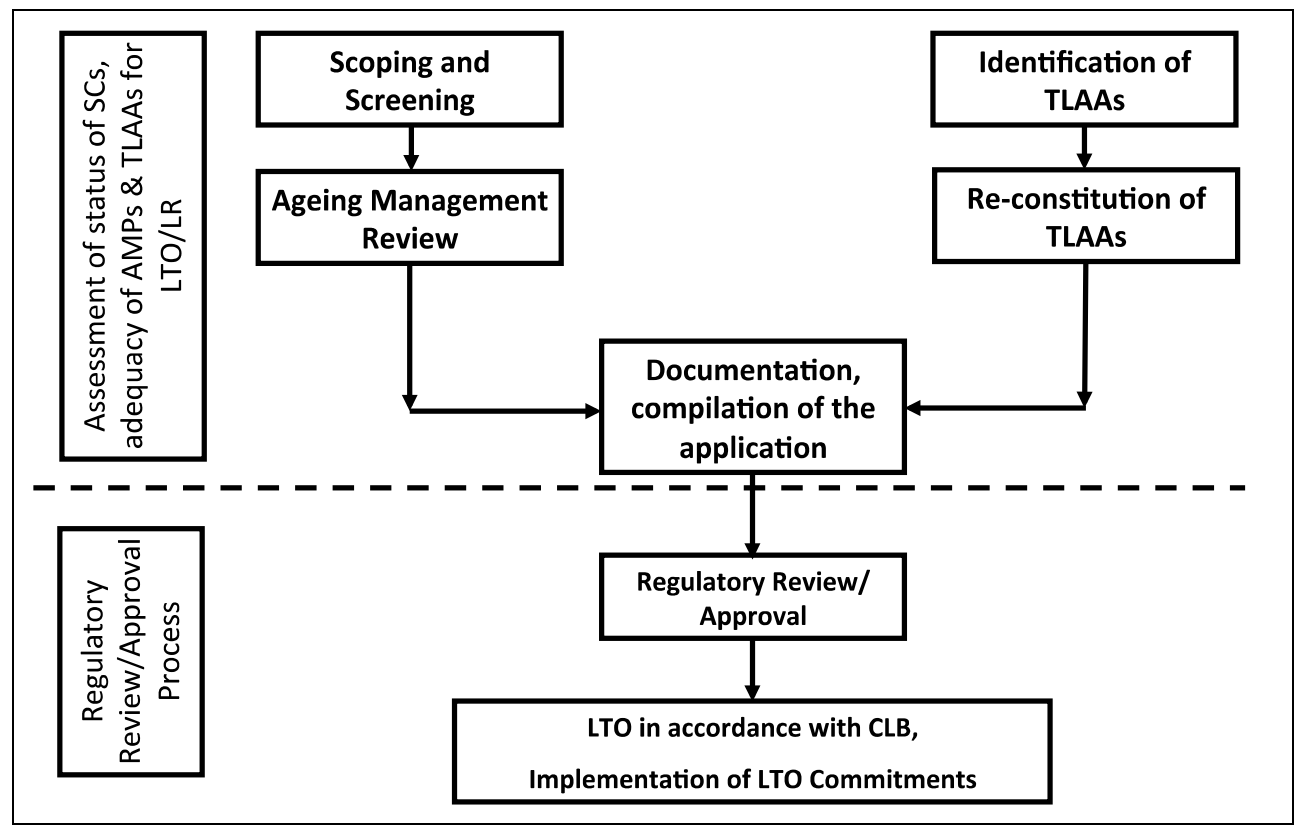

Fig. 10. Logic of the justification of licence renewal application 
In the VVER operating countries, licensing of extended operation is rather complex it requires obtaining the environmental licence for extended term of operation and other permissions. This system of licensing is shown in Fig.11.
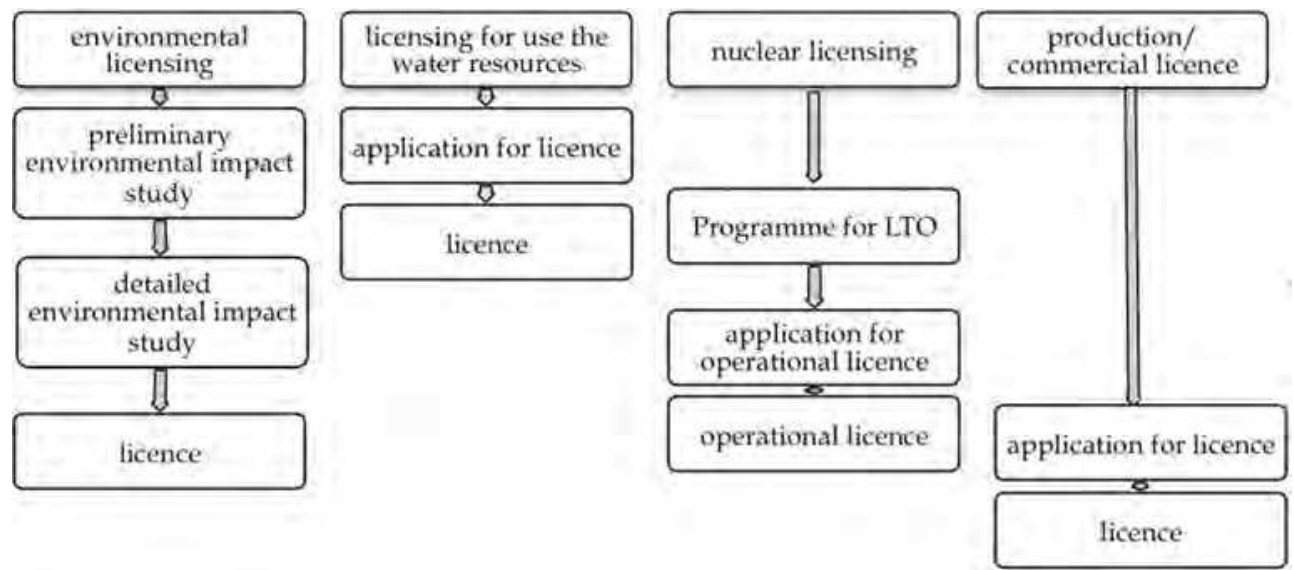

Fig. 11. Flowchart for licensing of extended operational lifetime

\section{Review of the plant condition}

Independent from the regulatory framework for approval of LTO, plant actual condition has to be reviewed and assessed. In the framework of licence renewal, the review of plant condition is part of the integrated plant assessment. In case of periodic safety review, the review of the plant condition is the review area of the safety factor 2 in accordance with IAEA Safety Guide NS-G-2.10 (IAEA, 2003).

The goal of the review is to evaluate and demonstrate the good health and their function and performance in line with requirements.

The scope of the review covers the following SSCs:

1. SCs with highest safety importance - safety class 12 and 3;

2. those non-safety SCs which can jeopardize the safety functions;

3. non-safety related SSCs which can jeopardize the environment (non-nuclear pipelines and tanks for storing different chemical substances);

4. SSCs important for production (turbine cooling water distribution panels etc.).

The review of plant condition is based on the information related to the health of components from the following sources:

- results of operational information records of the operational events;

- failure data root-cause analysis failure statistics;

- $\quad$ outage and maintenance records.

The evaluation can result in:

- modification of the maintenance procedures;

- modification of the periods of the maintenance;

- introducing new diagnostic measures in order to determine the necessary additional actions; 
- performing additional evaluation of the situation;

- modifications e.g. implementation new sealing;

- $\quad$ replacement of the component for a different type.

The inspection program for safety class $1 \mathrm{SCs}$ is the most rigorous one. It includes the following:

- data of the non-destructive testing of the SCs;

- evaluation of the results of the in-service inspections;

- evaluation of the results/findings of the maintenances;

- $\quad$ evaluation of the results of the ageing management programs;

- evaluation of failure data and other lifetime information;

- evaluation of operational information.

The non-destructive testing is a regular activity at the power plants. However, in the frame of the plant review for the justification of LTO some additional tests might be necessary. Individual programs can be useful and developed for the Class 1 SCs, i.e. for the reactor main isolation valves (if exist), main pipelines of primary loops, steam generators and pressurizer.

In case of groups (2)-(4) of SCs listed above, the methodology of the inspection for reviewing the plant condition is based practically on the information sources as in case of the group (1). However, the review method is the visual on-site inspection. Application of the graded approach is useful, i.e. in case of higher importance or safety relevance the inspection has to be performed for each particular item while the review can be limited to the inspection of a representative sample of the commodity. The selection of the representative sample has to be made taking into account the type material dominating degradation mechanism environmental stressors etc.

There are very trivial questions or aspects to be checked during the inspections for example:

- symptoms of leakages

- condition of the insulation;

- condition of painting;

- condition of surfaces without painting;

- condition of welding;

- condition of component at junction point of different materials;

- condition of bolted joints etc.

After performing all of the on-site inspections, the findings have to be evaluated and the corrective measures have to be identified. The information obtained has to be taken into account while reviewing the ageing management programmes and TLAAs.

\section{Ageing management}

Ageing management programmes (AMPs) might be preventive, mitigating of consequences of ageing or slowing down the process like the chemistry programmes.

There are programmes for monitoring of the condition and/or performance of SCs assuming that effective measures might be implemented for compensating the ageing effect and ensuring the required function.

The attributes of ageing management programmes are defined by the national regulations and the IAEA Safety Guide NS-S-G.12 (IAEA, 2009). All these definitions are similar to each other and to the definition given by the NUREG-1801 (US NRC, 2010). 
According to the flowchart in Fig.10, the plant has to define the scope of its ageing management and has to review the adequacy of the existing programmes.

Plant routine programmes e.g. the in-service inspection programme might be credited as adequate for ensuring the safety of the LTO if they can be qualified by the review.

\subsection{Scope of the ageing management}

\subsubsection{Generic approach}

Scope of ageing management programmes covers all safety-classified passive, long-lived structures and components, which have to perform intended safety function during operational lifetime. These are the safety and seismic classified SCs. Those non-safety structures and components have to be included into the scope failure of which may inhibit/affect the safety functions.

Depending on the national regulation, the definition of the scope, of ageing management may vary. The scope of AMPs can be extended to the components and equipment having high operational value too.

The starting point of the process is the definition of the safety and seismic classified SSCs. From that scope the SSCs have to be screened those, which are active and short-lived, i.e. in the scope of maintenance and scheduled replacement. The long-lived SCs requiring environmental qualification fall also out. The logic of the definition of the final scope of ageing management after scoping and screening is shown in Fig.12. Furthermore, and it is not indicated in the Fig.12 those SCs have to be also excluded, long-term operation of which will be justified via revalidation of TLAAs only. A very similar flowchart is given in (IAEA, 2007).

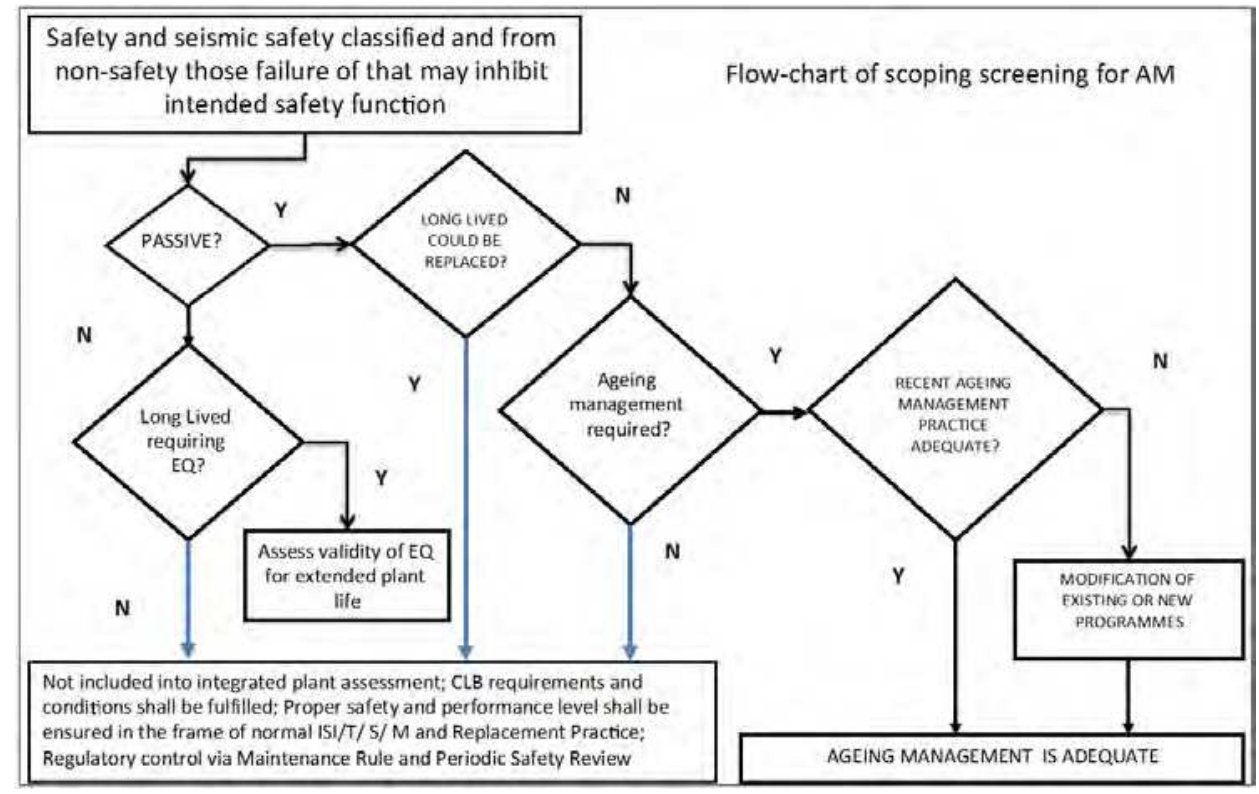

Fig. 12. Flowchart for scoping and screening for ageing management and AM review

Typical set of SCs within the scope of ageing management are as shown in the Table 1; see (Katona et al, 2005) and (Katona et al, 2009b): 


\begin{tabular}{ll}
\hline & SCs within the scope of AM \\
\hline Reactor pressure vessel (RPV) & Pressurizer \\
Reactor vessel internals & Hydro-accumulators and other SSCs of ECCS \\
Reactor vessel supports & Pumps valves and piping of safety classes 2 and 3 \\
Control Rod Driving Mechanisms & Emergency diesel-generator \\
Reactor cooling system (RCS) & Containment isolation valves \\
Piping connected to RCS & Feed-water piping pumps valves \\
Steam generator & Safety related heat exchangers \\
Main circulating pump & Piping and component supports \\
Main gate valves & Containment ventilation system \\
\hline
\end{tabular}

Table 1. SCs within the scope of ageing management

The IAEA Safety Guide on ageing management interpret the scope of AM including all systems structures and components relevant to safety (IAEA, 2009). Some VVER operating countries ageing management deals with both active and passive components and structures.

\subsubsection{Specific features of the VVER-440/213 plants}

First essential peculiarity of VVER-440/213 design is related to the extreme large number of safety-classified systems structures and components. In case of Paks NPP, the number of SSCs within Safety Classes 1-3 is over hundred thousand because of design features and methodology of safety classification.

The number of passive long-lived of SCs is also very large. After screening out the active and short-lived systems from the total safety classified SSCs approximately 38000 mechanical 6500 electrical and 2000 structural SCs have been identified to be in scope.

This magnitude of the scope multiplies all the ageing management effort of the plant. Methods should be applied for reasonable management of this large scope, e.g. careful structuring is required for effective organisation of ageing management and proper IT tools have to be developed for support of organisation of ageing management and dealing with information related to condition of the SCs (Katona et al, 2008).

\subsection{Structuring of ageing management programmes}

The VVER plants developed different types and system of ageing management programmes e.g.:

1. Plant overall AMP.

2. AMPs addressing a degradation mechanism.

3. Structure or component oriented AMP.

\subsubsection{Plant overall AMP}

Plant overall AMP can be developed and implemented for definition of the goals of the operating company distribution of the responsibilities and organizational performance and policy level activities definition of the structure of the system for ensuring the required plant condition, i.e. the implementation of the concept shown in Fig.9. Several VVER operating countries have utility or even industry level or umbrella type ageing management programmes like Ukraine. The plant level programme has to be deduced from the overall one furthermore the unit level programme from the plant level one. The plant overall AMP also includes the categorisation of the SCs in accordance to the safety relevance importance and complexity. Considering the structuring and organisation of AMPs, graded approach 
should be applied according to the safety relevance of the given structure or component and plant lifetime limiting character of the given ageing mechanisms.

\subsubsection{AMPs addressing a degradation mechanism}

AMPs addressing a particular degradation mechanism are listed in the Table2.

\subsubsection{Structure or component oriented AMP}

Applying the graded approach the SCs can be separated into two categories:

1. Highly important from safety point of view items with complex features and ageing mechanisms;

2. Items, e.g. pipelines pipe elements valves heat exchangers which have the same type safety class identical design features materials operating circumstances dominating ageing mechanism could be grouped into commodity groups and for each commodity group a designated AMPs should be implemented.

The highly important SCs like reactor pressure vessel together with internals components of main circulating loop (SCs of Safety Class 1 and some SCs of Class 2) can have dedicated individual AMPs, which are composed from several programmes, each of them is addressing one of the degradation mechanism critical location.

A structure or component oriented AMP is effective for determining the actual condition of specific structure or component or part of a complex SCs (control rod drives) for example:

a. Reactor pressure vessels

b. Steam generators

c. Reactor pressure vessel internals

d. Pressurizers

e. Main circulation pipeline

f. Main coolant pumps

g. Main gate valves

There are items, e.g. pipelines pipe elements (elbows T-pieces) valves heat exchangers, which can be grouped into commodity groups according to type material working environment. The SSC within a group have the same degradation mechanism and about the same operational and maintenance history. It is very reasonable to develop specific ageing management programmes addressing ageing of commodity groups. The definition of the commodity groups is performed applying the attributes given in the Table 3 in all reasonable combinations.

\begin{tabular}{ll}
\hline \multicolumn{2}{c}{ AMPs addressing a particular degradation mechanism } \\
\hline Low-cycle fatigue & Thermal ageing \\
Irradiation damage & Stress corrosion \\
Boric acid corrosion & Wear \\
Local corrosion & General corrosion \\
Irradiation assisted stress corrosion & Loosening \\
Swelling & High-cycle fatigue \\
Thermal stratification fatigue & Erosion \\
Erosion-corrosion & Microbiological corrosion \\
Water hammer & Groundwater corrosion \\
Deposition & \\
\hline
\end{tabular}

Table 2. AMPs addressing a particular degradation mechanism 


\begin{tabular}{llll}
\hline Safety classification & Type of SSC & Medium & Material \\
\hline Safety Class 1 & Valve body & Borated water & Stainless \\
Safety Class 2 & Pump body & Prepared water & steel \\
Safety Class 3 & Pipe and pipe & River/see water & Cast \\
Non-safety class failure of which may & elements & Steam gas-steam & stainless \\
inhibit intended safety function & Heat exchanger & mixture & steel \\
& Tank & Acid or alkali & Carbon steel \\
& & Oil other & \\
\hline
\end{tabular}

Table 3. Attributes for the definition of commodity groups

\subsubsection{VVER-440/213 example - AM for civil structures}

The VVER-440/213 design is very much differing from the usual architecture of PWRs. In case of Paks NPP practically all building structures at the plant are within the scope. Most of these building structures are complex and heterogeneous from the point of view of structural design, layout, manufacturing and construction of members, material composition and contact with environment (Katona et al, 2009a). In case of Paks NPP it would be difficult to adopt the AMPs described in GALL Report (US NRC, 2010) where nine groups of building structures seven groups of structural components are defined, and ten ageing management programmes cover the whole scope. At Paks NPP, the large number and variety of building structures and structural components requires establishment of a hierarchical structure of ageing management programmes. The type A programmes have been developed for the SCs shown in Table 4.

\begin{tabular}{|c|c|}
\hline \multicolumn{2}{|c|}{ SCs addressed by A-type AMP } \\
\hline foundations & reactor support structure \\
\hline reinforced concrete structural members & equipment foundations \\
\hline $\begin{array}{l}\text { steel and reinforced concrete water } \\
\text { structures }\end{array}$ & carbon and stainless steel liners \\
\hline prefabricated panels & masonry walls \\
\hline earth structures & doors and hatches steel-structures \\
\hline cable and pipe supports & paintings and coatings \\
\hline penetrations & fire protection structures \\
\hline main building settlement & support structures of cabinets \\
\hline sealing's and isolation & corrosion in boric acid environment. \\
\hline
\end{tabular}

Table 4. SCs addressed by A-type AMP

These programmes are related to specific structures, i.e. structural commodities or specific ageing mechanisms (e.g. building settlement due to soft soil conditions). The control of leaktightness of the containment is also an A type programme which is related to the containment only.

The buildings having identified safety functions are composed from structural commodities. Using the type A programmes for specific structures (commodities) 30 programmes of type $\mathrm{B}$ have been composed which covers all plant building structures. These AMPs contain the identification of ageing effects and mechanisms to be managed the lists and details of the proper application of AMPs of type " $\mathrm{A}$ " to be applied while managing the ageing of the given building. The " $\mathrm{B}$ " type AMP also contains logistical type information since the accessibility of certain buildings is limited. 


\subsection{Steps of the development of AMP}

Practically the first step of the procedure of the development of the ageing management programme is the scoping-screening presented in Section 7.1 above. In strict sense the AMP can be developed in following sequence:

1. Identification of degradation mechanisms and locations susceptible to ageing

2. Identification of the mitigation and preventive measures

3. Identification of the parameters to be controlled

4. Definition of the method for the detection of ageing effects

5. Definition of the monitoring trending condition evaluation

6. Definition of the acceptance criteria

7. Identification of the corrective actions

8. Organising the administrative control

9. Organising the operational experience feedback

In the reality, the development is some kind of iterative process and steps are overlapping, as it will be shown below.

\subsubsection{Identification of ageing mechanisms}

The development of AMPs has to be started with the identification of the ageing mechanisms critical locations and effect of the ageing on the intended safety function. In case of AMP to be developed for a complex structure or component like reactor or steam generator, several mechanisms and critical locations can be identified. The material conditions and stressors are considered at this step of the AMP development. Examples for the mechanisms are listed in the Table 2.

In fact, the structuring of the ageing management programmes and the identification of the commodities depend form the identification of ageing mechanisms.

For example, a commodity group can be defined as follows, see Table 3: "Safety Class 3" + "Piping and pipe elements" + working in "prepared water" (e.g. feed-water line) + "carbon steel". As per experience, the dominating ageing mechanism of this group is the flowaccelerated corrosion (FAC), which is a degradation process resulting in wall thinning of piping vessels heat exchanger and further equipment made of carbon and low alloy steel. This degradation mechanism of the identified commodity group should be addressed by proper AMP which can be developed, e.g. via application of COMSY system (Zander, Nopper, Roessner, 2007) used by several VVER operators.

\subsubsection{Preventing measures}

The second step of the development of the AMPs is the identification of the means of preventing or controlling of the ageing. For example, the corrosion phenomena on the internal surfaces can be slowed down via adequate water chemistry parameters. General corrosion and soil corrosion may be reduced by coatings and ensuring the undamaged state of the coatings. The most effective way of avoiding boric acid corrosion is the timely detection and effective termination of leakages onto carbon steel elements, which are the subject of walk down inspections.

\subsubsection{Parameters to be controlled}

Identification of the parameters allowing the control of the degradation process is essential part of AMP development. Some parameters are indicating the evolution of degradation 
directly e.g. the wall thickness of piping. The water chemistry parameters can be used as indirect controlling parameters of all internal surface corrosion mechanisms.

\subsubsection{Definition of the method for the detection of ageing effects}

Most of the postulated ageing effects and their occurrence can be detected during the execution of the current programs of the plant as follows:

- Non-destructive testing performed in the frame of in-service inspection programs;

- Visual inspections performed in the frame of maintenance programs;

- Visual structural inspections;

- Walk-down inspections.

\subsubsection{Monitoring trending condition evaluation}

Definition of the methods for monitoring, trending and condition evaluation is the fifth step in the development of the AMPs. For example, the monitoring of the trend of fast neutron fluence absorption in the critical components of the reactor pressure vessel is one of the most important indirect ageing management elements. The monitoring of load cycles defined during design and of their parameters belongs to the ageing management of fatigue degradation mechanism. The monitoring of the number and growth of crack-indications found during material inspections and visual inspections in the frame of in-service inspection can be assigned to each local degradation phenomenon. The monitoring and trending of the value of wall thickness reduction could be taken into account in the case of degradation forms with general material loss. In the case of heat exchangers, the monitoring of the number of plugged tubes can be considered also as an ageing management program element.

\subsubsection{Acceptance criteria}

The acceptance criteria are expressed as a limit value for the controlled parameter of the ageing. The limit value corresponds to the performance or functioning with required margin, see Fig.1. Acceptance criteria have to be defined for each component or commodity for each degradation mechanism in relation with fulfilment of intended safety function. The acceptance criteria can be derived from stress calculations in case of allowable wall thickness of piping or fatigue calculation regarding allowable load cycles. The acceptance criteria for degradation phenomena entailing decrease of the brittle toughness are determined by the relevant TLAA analysis results. The compliance criteria for water chemistry parameters are defined in the relevant chemistry instructions.

\subsubsection{Corrective actions}

The damages not complying with the acceptance criterion should be repaired if it is possible. In case of fatigue CUF $>1.0$ appropriate fatigue monitoring focused in-service inspection programme can be implemented.

\subsubsection{Administrative control}

The administrative and organisation arrangements have to be defined for the performance of ageing management programmes. Appropriate plant procedures have to ensure the planning staffing performing documenting and management control of the AMPs. Proper 
system for documentation and reporting has to be established. Proper quality assurance plan has to be also developed for AMPs.

\subsubsection{Operational experience feedback}

A system for the verification of the effectiveness of AMPs and feedback of experience has to be in place at plants. In the case of the found damages, the degradation mechanism should be identified and then it should be evaluated whether the given degradation mechanism is properly managed by the AMPs.

\subsubsection{Crediting the existing plant programmes}

Review of the existing plant programmes can qualify these programmes for adequate for ageing management. For example, the following programmes can be classified as AMPs or part of AMPs:

- Preventive and predictive maintenance programme can be considered to be part of AMP because it is one of the solutions of ageing mitigation and it is also necessary for AM to obtain information on carried out preventive maintenance of SCs

- In-service inspection programme

- Functional Testing Programme - for active components if they are in the scope of AM.

\subsection{Review of the AMPs}

The nine generic attributes of an effective ageing management programme against which each ageing management programme should be evaluated are see (IAEA, 2009):

1. Scope of the ageing management programme based on understanding of the ageing

2. Preventive actions to minimize and control the ageing degradation

3. Detection of the ageing effects

4. Monitoring and trending of the ageing effects

5. Mitigating the ageing effects

6. Acceptance criteria

7. Corrective actions

8. Operating experience feedback and feedback of R\&D results

9. Quality management

The attributes above are for checking whether all steps for development of AMPs discussed above have been done properly and the practical effectiveness of AMPs ensure the intended safety functions and LTO goals.

\section{Analyses of ageing processes}

\subsection{TLAAs and their role of the in justification for LTO}

Although the wording is sometimes different, the term "time-limited ageing analyses" is understood by the VVER operators in a very similar way as it is defined in US NRC Code of Federal Regulation 10CFR Part 54 Requirements for Renewal of Operating Licenses for Nuclear Power Plants. The role of the review and revalidation of the TLAAs in the justification of LTO is also the same as in the international practice.

The TLAAs are those calculations and analyses that:

1. Involve systems structures and components within the scope of LTO;

2. Consider the effects of aging; 
3. Involve time-limited assumptions defined by the current operating term for example in case of VVERs considered 30 years;

4. Were determined to be relevant by the licensee in making a safety determination;

5. Involve conclusions or provide the basis for conclusions related to the capability of the system structure and component to perform its intended functions; and

6. Are contained or incorporated by reference in the CLB..."

Existing TLAAs should be reviewed and revalidated with assumed extended time of plant operation. The evaluation of each identified TLAA should justify that the safety function of the SC will remain within design safety margins during the period of LTO.

The plants have to demonstrate either in the frame of the PSR or in the licence renewal application that:

- The analysis remains valid for the period of long-term operation;

- The analysis has been projected to the end of the period of long-term operation; or

- The effects of ageing on the intended function(s) will be adequately managed for the period of long-term operation.

There are three possibilities for validation of the TLAAs:

- It is possible to extend the validity the TLAAs;

- It is possible to remove the conservatism used in the TLAA analysis by less conservative assumptions and methods for analysis. It practically means to perform a new analysis.

- It is possible to demonstrate that measures will be introduced during the extended service life which will control the ageing processes and ensure the intended safety function.

\subsection{The scope of the required analyses}

The identified TLAAs cover the usual areas as fatigue calculations assessment of embrittlement changes of material properties etc. However, the scope of TLAAs in case of some VVERs is differing from the usual one either because of the peculiarities of the design or because of national regulation. For example, in case of Paks NPP, the scope of fatigue calculations is extended to the Safety Class 1 and 2 piping and components, and the analysis of thermal stratification is included. Regarding RPV, besides of PTS analysis, the limits and conditions of safe operation, i.e. the $\mathrm{p}-\mathrm{T}$ curve has to be re-analysed in the frame of revalidation of TLAAs.

\subsection{The issue of the TLAAs}

Review and validation of TLAAs is a rather complex task for majority of VVER plants. The issue is related to the availability of design base information and incompleteness of the delivered design documentation. Often the results of the analyses are known only; in some cases, the analyses are presumably obsolete.

The TLAAs have to be reviewed and verified for most important structures and components by control calculations using state-of-the-art methods. In many cases, the analyses have to be newly performed in accordance with the recent requirements.

Development of methodology of TLAA reconstitution and definition of the way of adaptation of ASME Boiler \& Pressure Vessel Code Section III (ASME BPVC) for a Soviet designed plant has been reported in (Katona, Rátkai, Pammer, 2007) and (Katona, Rátkai, Pammer, 2011). Hungarian regulations require application of state-of-the-art methods codes 
and standards while performing the time-limiting ageing analyses. ASME BPVC edition 2001 had been selected for the reconstitution of TLAAs and associated strength verification. The code selection requires understanding of both the Russian (Soviet) design standards and the ASME BPVC code. Different studies were performed for ensuring the adequacy of ASME BPVC implementation for VVER-440/213.

Calculations were performed for 50 years extended operational lifetime with additional margin of 10 years.

Comparing the practice of different VVER operating countries probably the most complex cases are the Eastern-European VVER-440/213 plants since these plants have to solve the issue indicated. The case of Paks NPP Hungary will be discussed below based on the (Katona et al, 2010).

\subsubsection{Mechanical components}

For justification of safety of long-term operation, the scope of TLAAs to be reconstructed or newly performed covers the Class 1 and 2 mechanical components. Examples of the calculations/analyses are as follows:

Low cycle fatigue analysis for Safety Class 1 and 2 piping and mechanical components:

ASME BPVC was adapted for the calculations; see (Katona, Rátkai, Pammer, 2011). This task also includes identification of needs for fatigue monitoring. Part of the analyses has already been performed. This justified the operability of the Class 1 and 2 piping and components for $50+10$ years.

There are only a few non-compliances found.

Most critical ones are the high stresses in the body and sealing block of the main circulating pumps. These however could be managed via focused non-destructive examination programs.

Analysis for thermal ageing of Class 1 and 2 components:

This task focuses on components manufactured from 15Ch2MFA 22K 08Ch18N9TL casted stainless steel materials and on welds (Sv04Ch19H11M3 EA400/10T Sv10ChMFT IONI 13/55), which are sensitive to thermal embrittlement.

Change of crack propagation resistance due to thermal embrittlement has been evaluated. Significant changes of material properties due to thermal embrittlement are expected in case of ferrit-pearlit materials or casted stainless steel above $220^{\circ} \mathrm{C}$ operational temperature.

Only a few components comply with these conditions at Paks NPP.

According to fatigue analyses, there are no cases where crack propagation due to fatigue might be expected. The analysis performed for the main gate valve casted stainless steel body shows that crack propagation should not be expected even if the J-R curve for C8 steel is changing due to embrittlement and a crack is postulated.

Analysis of thermal stratification for Class 1 and 2 pipelines:

A measuring system was operated at Paks NPP Unit 1 pressurizer surge line in 2000-2001. Assessment of measured data shows significant thermal stratification $\left(110^{\circ} \mathrm{C}\right)$, which moved periodically from the pressurizer to the hot leg. This temperature swing was kept by the swing of water level control in the pressurizer during the heat-up and cool-down. During normal operation, the temperature differences were decreased to a negligible level.

A similar temperature monitoring system is operating on both legs of surge line at Unit 3 since 2007. Evaluation of the measured data and the subsequent fatigue analysis justify the long-term operation for the pressurizer surge lines. 
Other pipelines have also been identified where thermal stratification might be the case, e.g. the pipelines connecting the coolant cleaning system No 1 to the primary system the pipeline of passive emergency core cooling system the feed water system pipeline and also the auxiliary emergency feed water pipelines. Experience gained at other VVER-440/213 plants (Mochovce and Dukovany NPP) has been taken into account while the pipelines of interest have been identified. Implementation of monitoring programs is going on these pipelines with temperature and displacement measurements.

High cycle fatigue analysis of flow-induced vibration of internal structures of the steam generator tubes:

This analysis shows that the flow-induced vibration of the heat-exchanging tubes does not cause significant stresses compared to those due to operational loads. Taking into account 60 years of operation and $108 \%$ of reactor thermal power the CUF is equal to 0.027 due to vibration even if a pipe wall thinning of $50 \%$ is assumed.

Analysis of the corrosion of piping wall:

The question is whether the erosion-corrosion allowance applied in the design provides sufficient margin for 50+10 years of operation. The analyses are supported by the data obtained from the erosion-corrosion program, which was implemented practically from the start of operation of the plant. The measured/observed rate of wall thinning is compared to those postulated in the design.

Few cases are expected only where the existing corrosion-erosion monitoring program using COMSY software has to be extended.

Analysis for material property change of the steam generator tubes:

The main finding of the study is that the thermal ageing of $08 \mathrm{H} 18 \mathrm{~N} 10 \mathrm{~T}$ material of heat exchanging tubes is negligible at operating temperatures $\sim 290^{\circ} \mathrm{C}$. Similar results were obtained from the destructive testing of piping of RBMK reactors made from the same material and working at the same operational temperatures. The material properties provided by the manufacturer can be used while selecting the standardized fatigue curves for the heat exchanging tubes. Results of laboratory tests show that there is no change in the fatigue crack propagation rate due to long-term operation at $288^{\circ} \mathrm{C}$; see (NPO Hidropress, 2007).

An operational time of 60 years is justified with this respect.

Crack propagation analysis of detected defects in Class 1 and 2 components:

The results of the analyses show that the detected defects are not critical from crack propagation point of view. The retrospective sampling performed for the RPV analysis does not lead to fracture mechanical consequences. The qualification defect sizes of nondestructive testing are also found adequate. The size of acceptable defects should also be reduced in the cases of cracks through cladding and of the longitudinal welds of steam generators. In the frame of this task, the embedded cracks in the heat affected zone below the RPV cladding, which are caused by inter-granular segregation will be analysed.

\subsubsection{Reactor pressure vessel and internals}

For the justification of operability of RPV and RPV internals for extended operational lifetime, the following analyses have to be performed:

PTS analyses for RPV

The structural integrity against brittle fracture of the RPV is ensured if the factual ductilebrittle transition temperature (DBTT) of its critical components is less than the maximum 
allowable component-specific DBTT. The analysis is based on the comparison of the static fracture toughness of the material and stress intensity factor calculated from the given loading situation (Linear Elastic Fracture Mechanics or LEFM concept).

Steps of the analysis are as follows:

- Identification of the critical components of the RPV: These are the parts of RPV belt line region (base metal circumferential weld No. 5/6 heat affected zone of the weld cladding) as well as the other circumferential welds of the RPV including the nozzle region.

- Selection of the PTS initiating events: Beyond the PTS initiating events selected on the basis of engineering judgment (LOCAs, stuck open pressurizer safety or relief valve, primary to secondary leakage accidents, etc.) additional transients are also considered if the frequency of occurrence is higher than $10^{-5} / \mathrm{a}$.

- Thermal-hydraulic calculations: These calculations provide the temperature fields in the down-comer distribution of heat transfer coefficient and pressure of reactor coolant as a function of time.

- Calculations of neutron fluences: Based on core configurations implemented so far and planned to be implemented in the future calculations using KARATE core design code (Kereszturi et al, 2010) and MCNP code (Breismeister, 2000) were performed. End-oflife fluences (for 50 and 60 operating years) are calculated for the RPV wall as well as for the surveillance position. Neutron dosimetry results have been used to verify the calculations.

- Temperature and stress field calculations: Temperature distribution in the RPV wall is determined for the analysed transient as a function of the coolant temperature and heat transfer coefficient between coolant and wall. Deformation and stress fields occurring because of the temperature transient and pressure inside the vessel are determined by solving the system of equations of elasticity (and/or plasticity).

- Fracture mechanics calculations.

Temperature deformation and stress fields are determined using axial-symmetric and/or simplified 3D models with global meshing and without crack; deformation and stress fields are determined based on linear deformation theory using linear-elastic material model.

A full-scope 3D FEM calculation should be used for those cases where the calculation outlined above would show that any transient could challenge the RPV integrity. In this case the FEM mesh contains a crack model with local meshing; determination of deformation and stress fields is based on theory of large deformations using elastic-plastic material models and von Mises theory; the stress intensity factor is determined from J-integral based on the theory of virtual crack increment.

Transients with annual frequency $\geq 10-5 /$ a have been analysed using the LEFM approach. For the two most significant transients further analyses have been conducted applying the Nonlinear Fracture Mechanics theory (Elastic Plastic Fracture Mechanics) to verify the results coming from the LEFM approach. This double check justified the appropriate conservatism of the LEFM approach.

The conclusion of the analyses is that the RPVs at Paks NPP can be safely operated for at least 60 years. For the sake of completeness of the studies, some additional analyses are still going on regarding for PTS sequences initiated by internal fires flooding and earthquakes under shutdown conditions. 
The neutron fluences also have to be modified taking into account the new fuel design introduced after power up-rate. These additional studies are not expected to change the conclusion.

Definition of pressure-temperature ( $p$-T) limit curves of RPV

The Hungarian Authority issued recently a new guideline to replace the old and quite conservative procedure for performing the RPV $\mathrm{p}-\mathrm{T}$ calculation. The old procedure considered the residual stresses with very high safety margin similarly to PTS calculations while the new guideline reduces this conservatism according to the present international practice. This new guideline will be the basis of calculations performed for the Unit $1 \mathrm{RPV}$. This task is interrelated to the tasks for review and justification of operational limits and conditions of the VVER-440/213 units at Paks NPP.

Analysis of fracture toughness of structures within the reactor pressure vessel

According to the preliminary results, the irradiation-assisted stress corrosion cracking and void swelling may be of interest. The stud joints fixing the polygon mantle to the core basket are the critical structures in case of both ageing mechanisms. The stress corrosion cracks might be initiated at the flange between the cap and threaded part of the bolt. The position of the cap may indicate the swelling.

Considering the radiation and temperature the segment No. 18 of the core basket is the most demanded. Measures can be identified after visual inspection of the core basket and review of inspection procedure.

The possibility of implementation of non-destructive volumetric test method for the bolts is also considered. With respect to the void swelling possibility of implementation of ultrasonic measurements as well as gamma heating and a replacement program are being investigated.

\subsubsection{Analyses related to operational limits and conditions}

Review of Final Safety Analyses Report and reconstruction of design bases, which has been performed at Paks NPP, resulted into recognition of need for justification of operational limits and conditions related to certain ageing phenomena via adequate thermo-hydraulic stress and fracture mechanics analyses. These analyses have been included into the scope of TLAAs required for the justification of long-term operation of Paks NPP. The task also includes the justification for modification of the limits and conditions in accordance with operational needs allowing rapid temperature changes in certain cases. The temperature measurements and the temperature rate control methodology have also been reviewed and amended.

Following analyses have been performed:

- confirmation of permissible cooling down heating up rates for the primary and secondary circuits

- analyses for confirmation of operational limits and conditions for the operational transients.

Analysis has been performed for the following components:

- RPV, RPV-head and RPV-flange;

- Primary side steam generator elements;

- Secondary side steam generator elements;

- Main isolating valve;

- Main circulating pump;

- Pressurizer tank; 
- Hydro-accumulators and their valves;

- Main steam system;

- Heat removal system.

The cases analysed are:

- The Normal Start-up Cycle

- The Normal Shutdown Cycle

- $\quad$ The Cycle Start-up from Operational Mode D

- The Rapid Cool-down Cycle

- Pressurizer Flow at Start-up

- The Pressurizer Flow at High Temperature Difference

- Injection at High Temperature Difference.

The main findings can be summarized as follows:

- The calculations performed for the given temperatures temperature rates and processes justify the adequacy of the limits and conditions defined by the designer.

- In case of injection into the pressurizer in accordance with existing limitation on temperature, the margin to allowable stress $(3 \mathrm{Sm})$ is minimal and the number of allowable cycles is rather small (6500) therefore monitoring of cycles shall be established.

- In case of rapid cool-down process a leakage of the inner sealing ring may occur, which can be controlled by leakage detection. Since the flanges of MIV are welded together, this will not result in leakage to the hermetic compartment.

- During the rapid cool-down process $\left(70^{\circ} \mathrm{C} / \mathrm{h}\right.$ cooling rate to reach the $150^{\circ} \mathrm{C}$ state) leakage may appear in the collector assemblies of the steam generators. However, the rapid cool-down may cause only the loosening of the inner sealing ring of the collector assemblies. Therefore, no primary coolant will get over to the secondary side.

According to existing prescriptions for the control of the heat-up and cool-down rates, the temperature has to be measured every minute and averaged over subsequent time-intervals of 19 minutes. The rate for the control has to be defined by taking the difference of the actual and the previous average temperature values. Compliance with hourly rate limit is ensured if the temperature change is less than $6.3^{\circ} \mathrm{C}$ for heat-up and $9.5^{\circ} \mathrm{C}$ for cool-down per every 19 minute interval. The performed analyses show that for certain components it is necessary to introduce ten minute averaging intervals with limitations of $33^{\circ} \mathrm{C}$ and $5^{\circ} \mathrm{C}$ per ten minutes corresponding to the rates of $20^{\circ} \mathrm{C} /$ hour and $30^{\circ} \mathrm{C} /$ hour respectively. The occasional applicability of the processes in primary system with rates $40^{\circ} \mathrm{C} / \mathrm{h}$ for heat-up and $60^{\circ} \mathrm{C} / \mathrm{h}$ for cool-down and for the rate of temperature change in the pressurizer is $80^{\circ} \mathrm{C} / \mathrm{h}$ have been justified as an amendment to the existing procedures. In these cases, the sudden temperature change should be avoided by appropriate temperature control.

The methodology of calculations was based on the adaptation of ASME BPVC. For the calculation of temperature transients in the primary system the RELAP5/mod3.3 code was used. Specific thermo-hydraulic model was developed for accident analyses. This model consists of detailed model of the primary system the heat removal system and the automatic control system and it takes into account the operator's actions during the heat-up and cooldown processes. The thermo-hydraulic model and the calculation method have been verified via comparison of the calculated transient time histories with the measured ones.

\subsubsection{Containment civil structures and structural components}

Taking into account the specific features of the VVER-440/213 design of civil structures and the lack/missing of analyses performed by the designer eight analysis tasks were identified 
as necessary for the justification of long-term operation of Paks NPP. Necessity of the performance of the stress calculations for the validation of the rather sparse information available for containment and other safety-classified structures were also recognized. Considering their content these calculations are not typical TLAAs. However, without sufficient information on the design of civil structures, the newly performed TLAAs would not have the design basis.

The scope includes the following tasks:

- Analysis of buildings classified into safety category for the verification of the design.

- Fatigue analysis for the containment penetrations;

- Fatigue analysis for the hermetic liner of the containment (welding transition welding area of anchors);

- Fatigue analysis for the liner of the spent fuel pool (welding transition welding area of anchors);

- $\quad$ Stress and fatigue analysis for the safety classified crane in the reactor hall with capacity of 250/32/ 2 tons;

In case of Paks NPP, there are several design-specific TLAAs of the main reactor building for example:

- Fatigue analysis of the containment for increased pressure level during integral leaktightness tests;

- Analysis of main reactor building settlement.

The allowable leakage value of the VVER-440/213 containment is 14.7 per cent per day at the design pressure of 2.5 bars. Each of the containments was tested at this design pressure in the start-up phase. The pressure of the yearly leakage tests is 1.2 bar and tests at a pressure of 1.7 bars are carried out during the outages. The leakage value for the nominal pressure of 2.5 bars is calculated via extrapolation from the leak-rate results of tests. This practice has been criticised regarding correctness of the leak-rate extrapolated from the measured ones. Therefore, investigations of enhancement of the test pressure level has been proposed. Nevertheless, the recent reduced pressure test procedure has obvious advantages compared to the tests at enhanced pressure level: the time needed for the low-pressure test is short and the load on containment structures is moderate. In the on-going analyses the test procedure covers all aspects of interest: Correctness of the leakrate defined via testing, the time consumption and the costs of the tests, and the fatigue due to cyclic loads are being considered and evaluated. According to the results of leaktests, the correct leakage values at the nominal pressure of 2.5 bars can be determined from the results of test out at considerably lower pressure values. This statement is based on analyses of numerous tests including the results of test carried out at the design pressure of 2.5 bars at Unit 2 in 2008.

Regarding Paks NPP, the analysis of settlement of the main building complex has been identified as a TLAA since an excessive inclination of the main building complex due to differential settlement may result in non-allowed tilting of the RPV vertical axis, which may cause problems with the control rods. Additionally, an excessive inclination can cause extreme local loading as well, resulting in degradations of the building. It has to be mentioned that the VVER-440/213 type units at Paks NPP have twin-unit-design, i.e. two main reactor buildings separated by a dilatation gap are built-up on a common base-mat.

Detailed settlement control was started during the construction period of Paks NPP. The measured results are to be evaluated and reported annually. A prolonged in time 
consolidation process was observed in case of the main reactor buildings the settlement of which is continuing. The phenomenon is related to the seasonal variation of the water level of the river Danube, which may reach a value of 9 meters. This variation of the river water level influences the ground-water level. According to the data measured in the wells at and around the plant site, the ground-water level follows the variation of the water level in the Danube with a certain time delay. The water-table fluctuations influence the stressdeformation conditions in the subsoil. This can explain the successive settlement of the raft foundation as measured during the past years. The settlement at Unit 4 is somewhat larger than at Units 1-3, which is due to the slight inhomogeneity of the subsoil and the highest alteration of the level of the water table occurring near Unit 4.

Detailed analyses have been performed for the subsidence and differential settlements of the main reactor buildings for the end-of-life situation taking into account the static loading (immediate settlement) ground-water fluctuation seismic settlement dynamic settlement due to machinery and tectonic subsidence. The calculation model and procedure has been calibrated to the measured time-history of subsidence. An adequate constitutive model has to be defined for the soil, which includes the development of a non-linear hardening model and proper definition of the decay curve for cyclic loading due to ground-water fluctuation based on soil tests results.

Regarding the long-term operation, the analyses show that a value of differential settlement that may cause non-allowed tilting of the RPV axis due to the inclination of the building should not be expected. The structural integrity of the foundation and the containment part of the main building structures is not affected by the settlement and it is not expected because of further subsidence.

\subsubsection{Basic findings of the revalidation/reconstitution of the TLAAs}

Dedicated ageing management programs already control some of the processes addressed by the presented above time-limited ageing analyses, e.g. process of settlement of the main building erosion-corrosion of piping wall.

The results of the above analyses show that only a few non-compliances or lifetime-limiting cases have been found and all of them can be managed by the extension/amendment of the existing ageing management programs and/or other plant programs.

For example, regarding RPV and internals the stud joints fixing the polygon mantle to the core basket are the critical structures from the point of view of irradiation-assisted stress corrosion cracking and void swelling. In order to manage these mechanisms, review and extension of the present programs are going on.

Regarding operational limits and conditions in case of injection into the pressurizer, the margin to allowable stresses is minimal and the number of allowable cycles is rather small. Consequently, the number of cycles should be monitored. It was also found that during certain heat-up and cool-down processes the averaging intervals of the temperature measurements have to be modified at certain components.

With respect to the containment civil structures, the existing ageing management program should be extended for managing the change of material properties of heavy concrete structures and to the corrosion of steel liner on heavy concrete surface.

Regarding electrical and I\&C components, cases were found where new ageing management programs are to be introduced or replacement of the equipment is needed. 


\section{Conclusions}

A complex picture of ensuring and justification of long-term operation of VVER plants is given in the Chapter; especially the VVER-440/213 model is discussed in details.

In VVER operating countries, proper regulatory framework and comprehensive plant lifetime management system have been developed for ensuring the safety of long-term operation of VVER-440 and VVER-1000 type plants. Detailed studies and already approved cases of prolongation of the plant operational lifetime are demonstrating the feasibility of long-term operation of VVER plants.

Generally accepted principles for safety have been followed while developing plant systems which ensure that any SSCs will be covered by some of the plant programmes and within the frame of LTO Programme all conditions of safe operation will be ensured. Significant for safe long-term operation structures systems and components are identified. Proper level of understanding of the ageing phenomena is reached and adequate ageing management programmes were developed for ensuring the required status and intended function for long-term. Revalidation of time-limited ageing analyses also justify the safety of long-term operation, which is completed by the monitoring of maintenance on performance criteria combined with the maintenance of environmental qualification and replacement/reconstruction programmes.

Best international practice and state-of-the-art methodologies have been applied while performing the particular tasks for preparation and justification of long-term operation and license renewal. However, as it has been demonstrated any good examples and experiences should be adapted in creative way taking into account the design features national regulations and existing plant practice.

This way the strategy of VVER operators to operate safely as long as possible and economically reasonable at higher power level will be ensured.

\section{References}

Breismeister, J.F. (2000). MCNPTM - A General Monte Carlo N-Particle Transport Code Version 4C LA-13709-M 2000

Czech Report (2010). The Czech Republic National Report under the Convention on Nuclear Safety Ref. No. 7972/2010 http://www.sujb.cz/docs/CZ_NR_2010_final.pdf

Erak, D.Yu. at al (2007). Radiation embrittlement and neutron dosimetry aspects in WWER440 reactor pressure vessels life time extension, Second IAEA International Symposium on Nuclear Power Plant Life Management, 15-18 October 2007 Shanghai China

IAEA (1992). Ranking of safety issues for WWER-440 model 230 nuclear power plants IAEA-TECDOC-640 IAEA Vienna

IAEA (1993). Proceedings of the SMiRT-12 Conference Seminar No. 16 on Upgrading of Existing NPPs with 440 and 1000 MW VVER type Pressurized Water Reactors for Severe External Loading Conditions. 23-25 August 1993 IAEA Vienna Austria

IAEA (1996a). Safety issues and their ranking for WWER-440 model 213 nuclear power plants IAEA-EBP-WWER-03 IAEA Vienna

IAEA (1996b). Safety issues and their ranking for WWER-1000 model 320 nuclear power plants IAEA-EBP-WWER-05 IAEA Vienna 
IAEA (2000). Safety issues and their ranking for WWER-1000 model "small series" nuclear power plants IAEA-EBP-WWER-14 IAEA Vienna

IAEA (2003). Periodic Safety Review of Nuclear Power Plants Safety Guide Safety Standards Series No. NS-G-2.10 International Atomic Energy Agency Vienna 2003

IAEA (2006). Plant Life Management for Long Term Operation of Light Water Reactors: Principles and Guidelines. Technical Reports Series No. 448. IAEA Vienna

IAEA (2007). Safety Aspects of Long term Operation of Water Moderated Reactors IAEAEBP-SALTO IAEA July 2007 Vienna

IAEA (2007). Strategy for Assessment of WWER Steam Generator Tube Integrity IAEATECDOC-1577 IAEA Vienna 2007

IAEA (2008). SALTO Guidelines. Guidelines for Peer Review of Long Term Operation and Ageing Management of Nuclear Power Plants. IAEA Services Series No. 17. Vienna International Atomic Energy Agency.

IAEA (2009). Ageing Management for Nuclear Power Plants IAEA Safety Standards Series No. Ns-G-2.12 International Atomic Energy Agency Vienna 2009 (ISBN:978-92-0112408-1)

Kadečka, P. (2007). Effective long term operation for Dukovany NPP, Second IAEA International Symposium on Nuclear Power Plant Life Management, 15-18 October 2007 Shanghai China

Kadečka, P. (2009). New PLiM program for Czech NPPs Proceedings of 2009 ASME Pressure Vessels and Piping Division Conference, July 26-30 2009, Prague, Czech Republic

Katona, T., Bajsz, J. (1992). Plex at Paks - making a virtue out of necessity. Nuclear Engineering International 37:(455) pp. 27-31.

Katona, T. (2006). Core tasks of long-term operation and their relation to plant processes at Paks NPP, PLIM + PLEX, 10-11 April 2006 Paris France

Katona, T.et al (2005). Key Elements of the Ageing Management of the VVER-440/213 type Nuclear Power Plants In: 18th International Conference on Structural Mechanics in Reactor Technology (SMiRT 18). Beijing, China 2005.08.07-2005.08.12. Paper D02-4.

Katona, T. (2010). Plant life management practices for water-cooled water moderated reactors (VVER) In: Understanding and mitigating ageing in nuclear power plants, Woodhead Publishing ISBN 9781845695118

Katona, T. et al (2001). Future of the Paks Nuclear Power Plant Lifetime-Management and Lifetime-Extension. In: Lifetime management: Proceedings of the 21st ESReDA seminar, Erlangen, Germany 2001.11.05-2001.11.06. Luxembourg: Office for Official Publications of the European Communities pp. 21-36.(ISBN:92-894-5665-5)

Katona, T. et al (2003). Main features of design life extension of VVER-440/213 units NPP Paks Hungary, ICONE 11th International Conference on Nuclear Engineering, Tokyo, Japan, April 20-23 2003

Katona, T. et al (2009a). Assessment and Management of Ageing of Civil Structures of Paks NPP. In: Proceedings of the ASME Pressure Vessels and Piping Conference. ASME 2009: Sustainable Energy for the Third Millennium. Prague, Czech Republic, 2009.07.262009.07.30. American Society of Mechanical Engineers p. CD-ROM. Paper PVP200977513. (ISBN:9780791838549)

Katona, T. et al (2009b). Extension of Operational Life-Time of VVER-440/213 Type Units at Paks Nuclear Power Plant In: Proceedings of the ASME Pressure Vessels and Piping Conference. ASME 2009: Sustainable Energy for the Third Millennium, Prague, 
Czech Republic 2009.07.26-2009.07.30. American Society of Mechanical Engineers, p. CD-ROM. Paper PVP2009-77911. (ISBN:9780791838549))

Katona, T. et al (2010). Time-limited Ageing Analyses for Justification of Long-Term Operation of Paks NPP. In: ASME International Mechanical Engineering Congress and Exposition. Vancouver Kanada 2010.11.12-2010.11.18. Paper IMECE2010-40201. (ISBN:978-0-7918-3891-4)

Katona, T., Rátkai, S. (2008). Extension of Operational Life-Time of VVER-440/213 Type Units at Paks Nuclear Power Plant. Nuclear Engineering and Technology 40:(4) pp. 269-276. (2008)

Katona, T., Rátkai, S. (2010). Programme of Long-term Operation of Paks Nuclear Power Plant. In: Transactions of ENC 2010: European Nuclear Conference 2010, Barcelona, Spain 2010.05.30-2010.06.02. Paper A0114. (ISBN:978-92-95064-09-6)

Katona, T., Rátkai, S., Pammer, Z. (2007). Reconstitution of Time-limited Ageing Analyses for Justification of Long-Term Operation of Paks NPP. In: 19th International Conference on Structural Mechanics in Reactor Technology (SMiRT 19). Toronto Kanada 2007.08.12. Paper D02/2-1.

Katona, T., Rátkai, S., Pammer, Z. (2011). Reconstitution of time-limited ageing analyses for justification of long-term operation of Paks NPP, Nuclear Engineering and Design, Volume 241 Issue 3 (March 2011) pp. 638-643

Kereszturi, A. et al (2010) General features and validation of the recent KARATE-440 code system, International Journal of Nuclear Energy Science and Technology 2010 - Vol. 5 No.3 pp. 207-238

Kupca, L. (2006). Irradiation Embrittlement Monitoring Programs of RPV's in the Slovak Republic NPP's, 14th International conference on nuclear engineering (ICONE 14), Miami FL (United States) 17-20 Jul 2006

NPO Hidropress (2007) Steam Generator PGV-213. Analysis of Material Properties of Steam Generator Tubes. (In Russian). NPO Hidropress Report No. U213D3 2007.

OECD NEA (2006). Nuclear Power Plant Life Management and Longer-term Operation OECD Publishing, NEA No. 6105. ISBN: 9789264029248 OECD Code: 662006111P1.

Orgenergostroy (1989a). Instruction of technical servicing for standardized units VVER-1000 NPP type B-320 containment pre-stressed system, Moscow, 1989

Orgenergostroy (1989b). Instruction of technical servicing for main series (nonstandardized) units VVER-1000 NPP type 302338 and 187 containment pre-stressed system, Moscow, Orgenergostroy, 1989

Popov, V. (2007). The large projects at Kozloduy NPP - with focus on long time operation and ageing management Second IAEA International Symposium on Nuclear Power Plant Life Management 15-18 October 2007 Shanghai China

Rosenergoatom (2003). Safety enhancement and lifetime extension of the power unit 1 of Kola NPP, Summary Report, Moscow, 2003

Slovak Report (2010). National Report of the Slovak Republic Compiled in Terms of the Convention on Nuclear Safety June 2010 http://www.ujd.gov.sk/files/dokumenty/NS_NS_2010.pdf

Šváb, M. (2007). Regulatory approach to the long-term operation of Czech Nuclear Power Plants Second IAEA International Symposium on Nuclear Power Plant Life Management 15-18 October 2007 Shanghai China. 
Trunov, N. B. et al (2006). Consideration of Field Experience in Developing New Projects of Steam Generators for Nuclear Power Stations Equipped with VVER Reactors, Thermal Engineering 2006 Vol 53 No 1 pp. 37-42

Trunov, N. B. et al (2006). WWER Steam Generators Tubing Performance and Aging Management 14th international conference on nuclear engineering (ICONE 14) Miami FL (United States) 17-20 Jul 2006

U.S. NRC (2010). Generic Aging Lessons Learned (GALL) Report - Final Report (NUREG1801 Revision 2)

Ukraine (2011). Состояние работ по реализации «Комплексной программы работ по продлению срока эксплуатации действующих энергоблоков атомных станций» http:/ / www.energoatom.kiev.ua/ru/Length_extension?_m=pubs\&_t=rec\&id=254 36

Vasiliev, V. G., Kopiev, Yu.V. (2007). WWER pressure vessel life and ageing management for NPP long term operation in Russia Second IAEA International Symposium on Nuclear Power Plant Life Management 15-18 October 2007 Shanghai China

Zander, A., Nopper, H., Roessner, R. (2007). COMSY - A Software Tool for PLIM + PLEX with Integrated Risk-Informed Approaches Transactions SMiRT 19 Toronto August 2007 Paper \# D02/4 


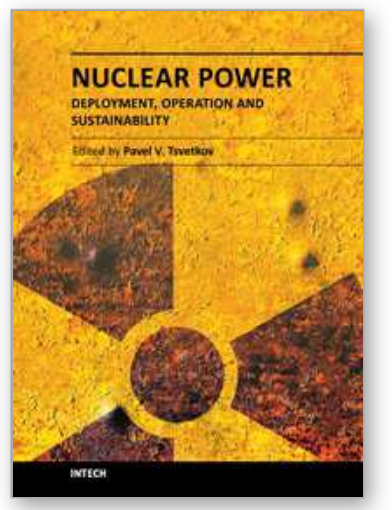

\author{
Nuclear Power - Deployment, Operation and Sustainability \\ Edited by Dr. Pavel Tsvetkov
}

ISBN 978-953-307-474-0

Hard cover, 510 pages

Publisher InTech

Published online 09, September, 2011

Published in print edition September, 2011

We are fortunate to live in incredibly exciting and incredibly challenging time. Energy demands due to economic growth and increasing population must be satisfied in a sustainable manner assuring inherent safety, efficiency and no or minimized environmental impact. These considerations are among the reasons that lead to serious interest in deploying nuclear power as a sustainable energy source. At the same time, catastrophic earthquake and tsunami events in Japan resulted in the nuclear accident that forced us to rethink our approach to nuclear safety, design requirements and facilitated growing interests in advanced nuclear energy systems. This book is one in a series of books on nuclear power published by InTech. It consists of six major sections housing twenty chapters on topics from the key subject areas pertinent to successful development, deployment and operation of nuclear power systems worldwide. The book targets everyone as its potential readership groups - students, researchers and practitioners - who are interested to learn about nuclear power.

\title{
How to reference
}

In order to correctly reference this scholarly work, feel free to copy and paste the following:

Tamás János Katona (2011). Long-Term Operation of VVER Power Plants, Nuclear Power - Deployment, Operation and Sustainability, Dr. Pavel Tsvetkov (Ed.), ISBN: 978-953-307-474-0, InTech, Available from: http://www.intechopen.com/books/nuclear-power-deployment-operation-and-sustainability/long-termoperation-of-vver-power-plants

\section{INTECH}

open science | open minds

\section{InTech Europe}

University Campus STeP Ri

Slavka Krautzeka 83/A

51000 Rijeka, Croatia

Phone: +385 (51) 770447

Fax: +385 (51) 686166

www.intechopen.com

\section{InTech China}

Unit 405, Office Block, Hotel Equatorial Shanghai

No.65, Yan An Road (West), Shanghai, 200040, China

中国上海市延安西路 65 号上海国际贵都大饭店办公楼 405 单元

Phone: +86-21-62489820

Fax: $+86-21-62489821$ 
(C) 2011 The Author(s). Licensee IntechOpen. This chapter is distributed under the terms of the Creative Commons Attribution-NonCommercialShareAlike-3.0 License, which permits use, distribution and reproduction for non-commercial purposes, provided the original is properly cited and derivative works building on this content are distributed under the same license. 